\title{
Strategic Complementarity, Fragility, and Regulation
}

\author{
Xavier Vives* \\ IESE Business School
}

December 2011

The paper analyzes a very stylized model of crises and demonstrates how the degree of strategic complementarity in the actions of investors is an important determinant of fragility. It is shown how the balance sheet composition of a financial intermediary, parameters of the information structure (precisions of public and private information), and the level of stress indicators in the market impinge on strategic complementarity and fragility. The model distinguishes between solvency and liquidity risk and characterizes them. Both a solvency (leverage) and a liquidity ratio are required to control the probabilities of insolvency and illiquidity. It is found that in a more competitive environment (with higher return on short-term debt) the solvency requirement has to be strengthened, and in an environment where the fire sales penalty is higher and fund managers are more conservative the liquidity requirement has to be strengthened while the solvency one relaxed. Higher disclosure or introducing a derivatives market may backfire, aggravating fragility (in particular when the asset side of a financial intermediary is opaque). The model is applied to interpret the 2007 run on SIV and $\mathrm{ABCP}$ conduits.

Keywords: stress, crises, illiquidity risk, insolvency risk, leverage ratio, liquidity ratio, disclosure, transparency, opaqueness, panic, run, derivatives market. JEL Codes G21, G28.

* An early version of the paper (October 2009) was circulated under the title "Stress, Crises, and Policy". I am grateful to Elena Carletti, Todd Keister, Arvind Krishnamurthy, Philipp Schnabl, Javier Suarez, Wolf Wagner, and participants at the Banking Workshop of the Public-Private Sector Research Center at IESE, the 2010 ESMFM at Gerzensee, the 2011 Banca d'Italia-CEPR Conference, the New York Fed, the Florence 2010 FIRS conference, the CAREFIN 2011 conference, seminars at Northwestern Finance, the University of Oslo, IIES (Stockholm University), EIEF, and the EFA and the EEA meetings in 2011 for very helpful comments, and to Rodrigo Escudero and Jorge Paz for able research assistance. The research leading to these results has received funding from the European Research Council under the European Advanced Grants scheme, Grant Agreement no. 230254 as well as from project ECO2008-05155 of the Spanish Ministry of Education and Science at the PublicPrivate Sector Research Center of IESE. 


\section{Introduction}

In a crisis situation, and the present financial crisis is a good example, things seem to go wrong at the same time and an adverse shock is magnified by the actions and reactions of the investors. ${ }^{1}$ In particular, liquidity evaporates while short-term investors rush for the exit, and a solvency problem may arise. The increased reliance on market funding of financial intermediaries, investment banks in particular but also commercial banks, has been blamed for the increased fragility. The demise of Northern Rock in 2007, and Bear Stearns and Lehman Brothers in 2008, or of the German IKB or Hypo Real State, are cases in point where the short-term leverage of the institutions was revealed as a crucial weakness of their balance sheet. ${ }^{2}$ In this context it has proved difficult to disentangle liquidity from solvency risk. The influence of the opaqueness of financial products, the impact of public news (such as those provided by the ABX index on residential-based mortgage securities, public statements about the health of banks ${ }^{3}$, or stigma associated to borrowing from the discount window which becomes known ${ }^{4}$ ), as well as the stabilizing or de-stabilizing influence of derivative markets are also debated. The crisis has put regulatory reform in the agenda. Policy makers and regulators are struggling with how to reform capital requirements, introduce liquidity requirements, and control markets for derivatives. ${ }^{5}$

The recent financial crisis has reopened the debate on whether crises are fundamentals or panic-driven. Friedman and Schwartz (1963) in their analysis of the Great Depression

1 See, for example, Brunnermeier (2009).

2 For example, in June 2007 wholesale funds represented about $26 \%$ of liabilities in Northern Rock (Shin (2009)) and short term financing represented an extremely high percentage of total liabilities in Lehman Brothers before the crisis (Adrian and Shin (2010)). Washington Mutual faced a withdrawal of $\$ 16.5$ billion of large deposits just in the two weeks before its collapse (according to the Office of Thrift Supervision). See also the evidence in Ivashina and Scharfstein (2010).

3 Such as the case of the run on IndyMac Bancorp in June 2008 which followed shortly after the public release of letters by Senator Schumer of the Banking Committee.

4 See Armantier et al. (2010).

5 See, for example, FSA (2009) and BIS (2009). The Dodd-Frank Act (2010) introduces a leverage limitation for financial holding companies above a certain size. BIS (2009) proposed two new liquidity ratios: a liquidity coverage ratio to cover short term cash outflows with highly liquid assets and a net stable funding ratio to cover required stable funding with available stable funds. It is worth noting that Bear Stearns was regulated by the SEC and was in fact subject to a liquidity requirement which proved ineffective in the crisis. 
argued forcefully that many bank failures arose out of panics, that is, because of liquidity rather than solvency problems. This would be consistent with the self-fulfilling view of crises of Bryant (1980) and Diamond and Dybvig (1983). Gorton (1988) disputed the view that crises are panic driven with a study of crises in the National Banking Era concluding that crises were predictable (see also Gorton (1985) and Schotter and Yorulmazer (2009)). The information view of crises has been developed, among others by Chari and Jagannathan (1988), Jacklin and Bhattacharya (1988), and Allen and Gale (1998). ${ }^{6}$ Calomiris and Mason (2003) dispute also the analysis of Friedman and Schwartz (1963) and conclude that some episodes of banking crises in the 1930s in the US can be explained by deteriorating fundamentals while others could be explained by a panic component dominating (as the crises in January and February of 1933). Starr and Yilmaz (2007) claim that both fundamentals and panic elements coexist in the explanation of the dynamics of bank runs in Turkey.

In this paper a model that bridges the panics and fundamentals view of crises is presented and it is shown how a worsening of some stress indicators may trigger a downward spiral by increasing strategic complementarity in the actions of investors and magnify the impact of bad news. The model disentangles liquidity from solvency risk and shows how their control needs both a solvency (leverage) and a liquidity requirement. It is found also that more transparency or adding a derivatives market may be counterproductive in terms of stability. This is particularly so when the asset side of a financial intermediary is very opaque.

The paper presents a very stylized model of a crisis where investors have to decide whether to keep the investment or run. The investment may be in a currency, bank, or short-term debt. A financial intermediary will be our main focus. The degree of strategic complementarity in the actions of investors, that is, how the actions of investors move together, is shown to be an important determinant of fragility. We characterize how the

6 Postlewaite and Vives (1987) present a model with incomplete information about the liquidity shocks suffered by depositors featuring a unique Bayesian equilibrium with a positive probability of bank runs. In their model there is no uncertainty about the fundamental value of the banks' assets and no solvency problems. 
degree of strategic complementarity depends on the balance sheet composition of a financial intermediary, parameters of the information structure of investors (precisions of public and private information), and the level of stress indicators in the market. In the case of a financial intermediary, strategic complementarity increases with a weaker balance sheet (higher leverage) and with stress indicators such as the required return of short-term debt of the bank (competitive pressure) or the level of the fire-sale penalty of early asset liquidation. A weaker balance sheet or an increase in stress indicators raises fragility, the probability of a crisis, and the range of fundamentals for which there is coordination failure from the point of view of the institution attacked (that is, when the institution is solvent but illiquid). Moreover, the impact of bad news, say a public signal about weak fundamentals, is magnified when strategic complementarity is high. At the same time public signals, coming for example, from a derivatives market, may be destabilizing (over and above the strict content of the news), and the more so the more precise they are. The results are consistent with the 2007 run on SIV and ABCP conduits.

The model is based on the theory of games with strategic complementarities with incomplete information (an example of which are the "global games" of Carlsson and van Damme (1993) and Morris and Shin (1998); see Vives (2005)). ${ }^{7}$ We provide a general framework, which nests among others the models of Morris and Shin (1998, 2004), Rochet and Vives (2004), and Bebchuk and Goldstein (2011). Our framework displays the link between strategic complementarity and fragility (by showing how the degree of strategic complementarity is the crucial parameter to characterize equilibrium and how strategic complementarity relates to the deep parameters in the model); delivers predictions both in the case where there is a unique equilibrium and where there are multiple equilibria; and characterizes illiquidity and insolvency risk and show how do they depend on the composition of the balance sheet of a financial intermediary. We typify how a regulator to control the probabilities of insolvency and illiquidity has to set solvency and liquidity requirements; and apply the model to interpret the 2007 run on SIVs and the role of a derivatives market.

7 The importance of strategic complementarities in macro models has been highlighted by Cooper and John (1988). 
The policy message that follows from the analysis is that a regulator, with the tools available, needs to pay attention to the composition of the balance sheet of financial intermediaries, in particular to the ratio of cash to unsecured short-term debt and to the short-term leverage ratio (ratio of unsecured short-term debt to equity or, more in general, stable funds). Those two ratios, together with the required return of short-term debt and parameters of the information structure, are crucial determinants of the probabilities of insolvency and illiquidity. Often minimum ratios on solvency (inverse of short-term leverage) and liquidity will be sufficient to control the probabilities of insolvency and illiquidity. It is found that in a more competitive environment (with higher return on short-term debt) the solvency requirement has to be strengthened, and in an environment where the fire sales penalty increases and fund managers become more conservative the liquidity requirement has to be strengthened while the solvency one relaxed. The introduction of a derivatives market should go together with tightened regulation.

The plan of the paper is as follows. Section 2 presents the basic model and examples. Section 3 characterizes equilibrium and its links with strategic complementarity. Section 4 analyzes illiquidity and insolvency risk and develops the comparative statics properties of equilibrium. Section 5 deals with solvency and liquidity regulation of a financial intermediary and Section 6 with the literature connections and evidence. Section 7 applies and extends the model to the 2007 run on SIV. Section 8 considers other applications. Concluding remarks close the paper. The Appendix collects the proofs of the propositions.

\section{The investors' game and a stylized crisis model}

Consider the following binary action game among a continuum of investors of mass one. The action set of player $i$ is $\{0,1\}$, with $y_{i}=1$ interpreted as "acting" and $y_{i}=0$ "not acting". To act may be to attack a currency, refuse to roll over debt, run on a bank or SIV or not renew a certificate of deposit in the interbank market. 
Let $\pi^{1}=\pi\left(y_{i}=1, y ; \theta\right)$ and $\pi^{0}=\pi\left(y_{i}=0, y ; \theta\right)$ where $y$ is the fraction of investors acting and $\theta$ is the state of the world. The differential payoff to acting is $\pi^{1}-\pi^{0}=B>0$ if $y \geq h(\theta ; \alpha)$, and $\pi^{1}-\pi^{0}=-C<0$ if $y<h(\theta ; \alpha)$, where $h(\theta ; \alpha)$ is the critical fraction of investors above which it pays to act and $\alpha$ will be an index of vulnerability or stress. We have that

$$
\begin{aligned}
& y>h(\theta ; \alpha) \quad y \leq h(\theta ; \alpha)
\end{aligned}
$$

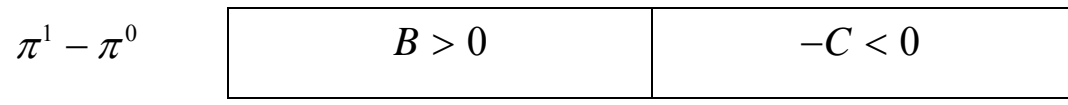

Let $\gamma \equiv C /(B+C)$ be the critical success probability of the collective action such that it makes an agent indifferent between acting and not acting. This is the ratio of the cost of acting to the differential incremental benefit of acting in case of success in relation to failure. An investor will "act" if his assessed probability of successful mass action is larger than $\gamma$. It is assumed that $h(\cdot)$ is strictly increasing, crossing 0 at $\theta=\underset{\sim}{\theta}$ $\left(\lim _{\theta \uparrow \theta} h(\theta)=0\right)$ and 1 at $\theta=\tilde{\theta}>\underset{\sim}{\theta}$, and smooth on $(\underset{\sim}{\theta}, \tilde{\theta}) .{ }^{8}$ A larger $\alpha$ means more vulnerability or a more stressful environment for the institution attacked since the threshold for the attack to be successful is lower. In the applications $h$ will be linear in $\theta$ in the relevant range:

$$
h(\theta ; \alpha)=h_{0}(\alpha)+h_{1}(\alpha)(\theta-\underset{\sim}{\theta}(\alpha)) \text { for } \theta \geq \underset{\sim}{\theta}
$$

and $h(\theta ; \alpha)<0$ for $\theta<\underset{\sim}{\theta}$.

The investors' game is of strategic complementarities since $\pi^{1}-\pi^{0}$ is increasing in $y .{ }^{9}$ In fact, $\pi\left(y_{i},(y, \theta)\right)$ has increasing differences in $\left(y_{i},(y,-\theta)\right)$. It follows from these payoffs, if the state of the world is known, that if $\theta<\underset{\sim}{\theta}$ then it is a dominant strategy to

8 Note that this allows the function $h(\cdot)$ to be discontinuous at $\theta=\underset{\sim}{\theta}$ with $h(\underset{\sim}{\theta})>0$ and $h(\theta)<0$ for $\theta<\underset{\sim}{\theta}$. We parameterize $h$ with a parameter $\alpha, h(\cdot ; \alpha)$, with $\partial h / \partial \alpha<0$.

9 In a game of strategic complementarities the marginal return of the action of a player is increasing in the level of the actions of rivals. This leads to best replies being monotone increasing. See Vives (2005). 
act; if $\theta>\tilde{\theta}$ then it is a dominant strategy not to act; and for $\theta \in \underset{\sim}{\theta}, \tilde{\theta})$ there are multiple equilibria. Both everyone acting and no one acting are equilibria. Since the game is a game of strategic complementarities there is a largest and a smallest equilibrium. That is, there are extremal equilibria. The largest equilibrium is $y_{i}=1$ for all $i$ if $\theta \leq \tilde{\theta}$, and $y_{i}=0$ for all $i$ if $\theta>\tilde{\theta}$, and it is (weakly) decreasing in $\theta$. This is a consequence of $\pi^{1}-\pi^{0}$ being decreasing in $\theta$.

From now on I consider an incomplete information version of the game where investors have a Gaussian prior on the state of the world $\theta \sim N\left(\mu_{\theta}, \tau_{\theta}^{-1}\right)$ and investor $i$ observes a private signal $s_{i}=\theta+\varepsilon_{i}$ with Gaussian i.i.d. distributed noise $\varepsilon_{i} \sim N\left(0, \tau_{\varepsilon}^{-1}\right) \cdot{ }^{10}$ It is worth noting that the prior mean $\mu_{\theta}$ of $\theta$ can be understood as a public signal of precision $\tau_{\theta}$. With this interpretation as a conditional expectation of $\theta$ for a given realization of a public signal, $\mu_{\theta}$ can be negative.

The model encompasses several crisis situations studied in the literature: currency attacks (Morris and Shin (1998)), loan foreclosure (Morris and Shin (2004)), credit freezes (Bebchuk and Goldstein (2011)), and bank runs (Rochet and Vives (2004)). We concentrate in the latter and examine the other examples in Section 8. Traditional bank runs were the outcome of massive deposit withdrawal by individual depositors. Modern bank runs are the outcome of non-renewal of short-term credit in the interbank market, like in the case of Northern Rock, the 2007 run on SIV, or the 2008 run by short-term creditors in the case of Bear Stearns or Lehman Brothers.

Consider a market with three dates: $t=0,1,2$. At date $t=0$, the bank has own funds $E$ (taken to include stable resources: equity, long-term debt and even insured deposits) and

10 This is referred to in the literature as a "global game". Those games were introduced by Carlsson and van Damme (1993) as games of incomplete information with types determined by each player observing a noisy signal of the underlying state. The goal is to select an equilibrium with a perturbation in a complete information game with multiple equilibria. The basic idea is that players entertain the "global picture" of slightly different possible games being played. Each player has then a noisy signal of the game being played. 
uninsured short term debt (e.g. uninsured wholesale deposits, certificates of deposit (CDs)) in amount $D_{0} \equiv 1$. These funds are used to finance risky investment $I$ and cash reserves $M$. The balance sheet constraint at $t=0$ is thus $E+D_{0}=I+M$. The returns $\theta I$ on these assets are collected at date $t=2$ and if the bank can meet its obligations, the short-term debt is repaid at face value $D$, and the equityholders of the bank obtain the residual (if any). Investors are also entitled to the face value $D$ if they withdraw in the interim period $t=1$. Let $m \equiv M / D$ be the liquidity ratio, $\ell=D / E$ be the short-term leverage ratio, and $d=D / D_{0}$ the return of the short-term debt. ${ }^{11}$

A continuum of fund managers makes investment decisions in the short-term debt market. At $t=1$ each fund manager, after the observation of a private signal about the future realization of $\theta$, decides whether to cancel $\left(y_{i}=1\right)$ or renew his position $\left(y_{i}=0\right)$. If $y>M$ then the bank has to sell some of its assets ${ }^{12}$ in a secondary market to meet payments. The early sale value of the assets of the bank involves a fire sales penalty $\lambda>0$ (retrieving only $\theta /(1+\lambda)$ for each unit invested). ${ }^{13}$

A fund manager is rewarded for taking the right decision (that is, withdrawing if and only if the bank fails). The cost of canceling the investment is $C$ and the benefit for getting the money back or canceling when the bank fails is $\hat{B}=B+C$. Again, $\gamma \equiv C /(B+C)$ is likely to be small since $B+C$ is the benefit to make the right decision. What is crucial is

11 The distinction of stable funds within liabilities is made also in the BIS (2009) document dealing with liquidity risk. The two ratios proposed in the BIS document are in fact equivalent in our simple formulation. The BIS short-term funds ratio would correspond to $m$ and the BIS net stable funds ratio to $E / I$. Note also that leverage $D /(D+E)$ equals $\left(1+\ell^{-1}\right)^{-1}$ and is monotone in $\ell$.

12 Or borrow against collateral in the repo market.

13 The parameter $\lambda$ could be related to the Libor-OIS spread (a measure of the difference between interbank rates and the rates paid on instruments which are not exposed to the default risk of intermediaries) which increased substantially both in August 2007 (start of the crisis) and September 2008 (Lehman Brothers' collapse). In case of secured collateral $\lambda$ relates to the haircut required. Haircuts on asset backed securities rose dramatically after the collapse of Lehman Brothers (see, e.g., Gorton and Metrick (2010)). It is important to remark that the liquidity requirements on broker-dealers in the US were related to unsecured funding while, for example, the demise of Bear Stearns in the end happened because of its failure to renew its secured funding. (See SEC's Oversight of Bear Stearns and Related Entities (SEC, 2008).) 
that investors, whatever the reason, adopt a behavioral rule of the type: cancel the investment if and only if the probability that the bank fails is above threshold $\gamma$. This rule will arise also if investors expect a fixed return when withdrawing, nothing if they withdraw and the bank fails, and there is a (small) cost of withdrawing. Note that a larger $\gamma$ is associated to a less conservative investor. Risk management rules may therefore influence $\gamma$.

Let $\underset{\sim}{\theta} \equiv(D-M) / I=(1-m) /\left(\ell^{-1}+d^{-1}-m\right)$, using the balance sheet constraint, be the solvency threshold of the bank $^{14}$, such that if $\theta<\underset{\sim}{\theta}$ the bank fails even if all fund managers renew credit to the bank; and $\tilde{\theta} \equiv(1+\lambda) \underset{\sim}{\theta}$ the "supersolvency" threshold, such that a bank does not fail even if no fund manager renews his CDs. Under these conditions the bank fails if

$$
y \geq h(\theta)=m+\frac{\ell^{-1}+d^{-1}-m}{\lambda}(\theta-\underset{\sim}{\theta})
$$

for $\theta \geq \underset{\sim}{\theta}$, and $h(\theta)<0$ otherwise. Here we have that $h(\underset{\sim}{\theta})=m>0$. We can denote the critical fraction by $h(\theta ; \alpha)$ letting $\alpha \equiv \lambda, \alpha \equiv d$ or $\alpha \equiv \ell$ since $h$ is decreasing in these variables. (See Figure 1.) If $1-\ell^{-1}-d^{-1}<0$, noting that $\operatorname{sign}\{\partial \underset{\sim}{\theta} / \partial m\}=\operatorname{sign}\left\{1-\ell^{-1}-d^{-1}\right\}$, we can let also $\alpha \equiv m^{-1}$ since then $h$ is increasing in $m$ (despite the fact that $\left.\partial h_{1} / \partial m<0\right) .{ }^{15}$

14 It is worth noting that the solvency threshold is related to what the FDIC calls the "Net Non-core Funding Dependence Ratio", as part of the CAMELS assessment, computed as non-core liabilities, less short-term investments divided by long-term assets.

15 We have that $\partial h / \partial m=\lambda^{-1}(1+\lambda-\theta)>0$ since $\theta<(1+\lambda) \underset{\sim}{\theta}<1+\lambda$ as $1-\ell^{-1}-d^{-1}<0$ implies that $\underset{\sim}{\theta}<1$. 


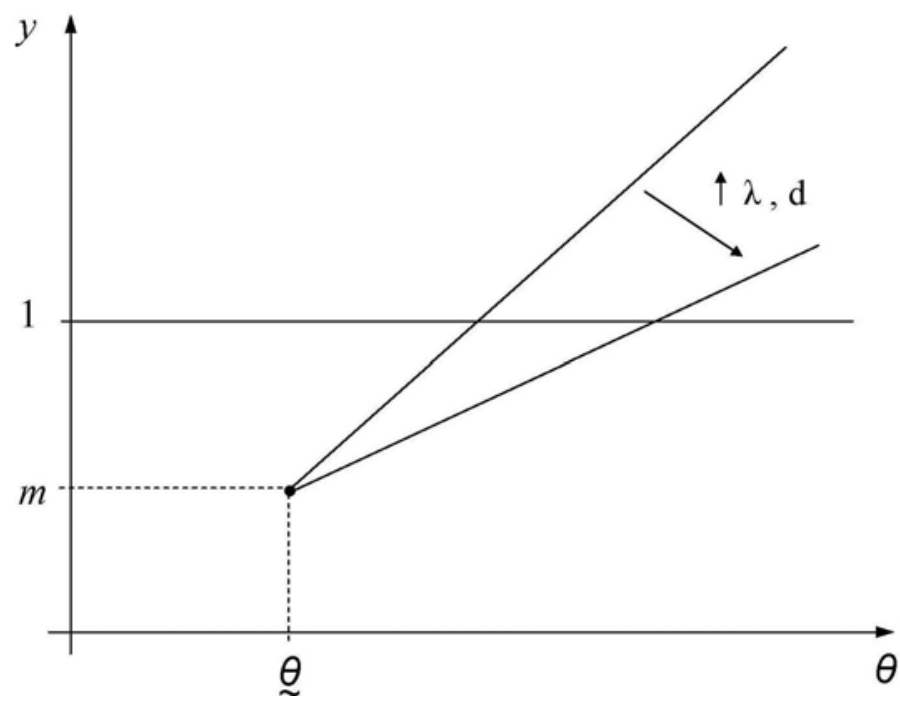

Figure 1. The function $h(\theta)=m+\left(\ell^{-1}+d^{-1}-m\right) \lambda^{-1}(\theta-\underset{\sim}{\theta})$ in the bank runs model.

In the balance sheet of a financial intermediary typically we have $1-\ell^{-1}-d^{-1}<0$. Indeed, the ratio of (uninsured) short-term debt over stable funds (equity, long term debt and insured deposits) $\ell=D / E$ is below 1 for commercial banks, and although it is above 1 for investment and wholesale banks typically $d^{-1} \geq .9$ (with an interest rate of at most $10 \%$ ), and therefore we would need $\ell^{-1}<.1$ or $\ell>10$ to have $1-\ell^{-1}-d^{-1}>0$. See Figure 2. ${ }^{16}$ For a typical SIV we have also that $\ell<1 .{ }^{17} \mathrm{We}$ assume henceforth, unless otherwise stated, that $1-\ell^{-1}-d^{-1}<0$.

16 Only State Street Corp. would go above $\ell=10$ with $\ell=14.77$ (which would yield $1-\ell^{-1}-d^{-1}=0$ with an interest rate of 7.26\%). Lehman Brothers had $\ell=3.76$ at the end of 2007 (derived from Adrian and Shin (2010)).

17 According to the Global Financial Stability Report of the IMF (April 2008), the typical funding profile of SIV in October 2007 was $27 \%$ in asset-backed commercial paper (ABCP) and the rest in mediumterm notes and capital notes. This would mean that $\ell=.34$. 


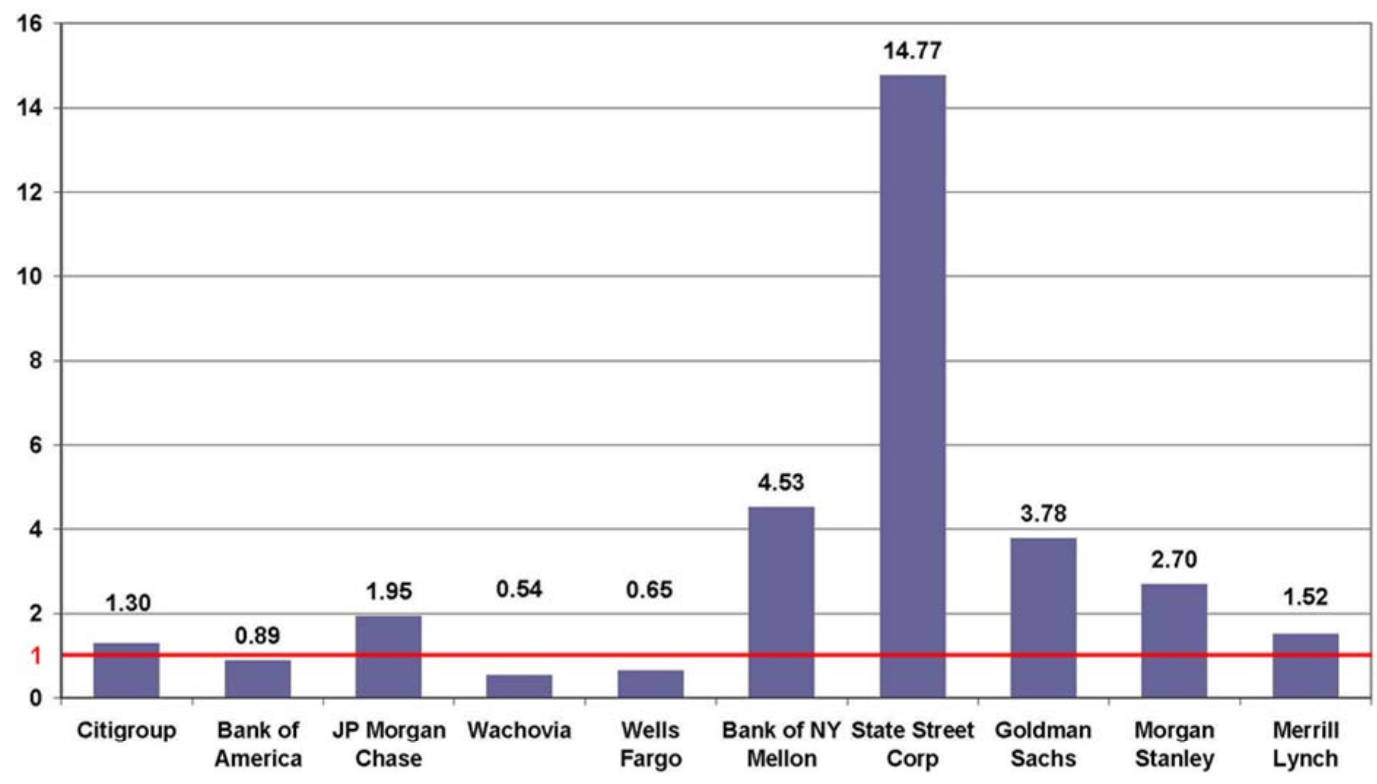

Figure 2: Short-term leverage ratio of US banks at September 30, 2008: $\ell=D / E, D=$ Deposits (Uninsured) + Short Term Debt + Other Liabilities, $E=$ Equity + Long Term Debt + Deposits (Insured). Source: Veronesi and Zingales (2010), (data for Goldman Sachs and Morgan Stanley as of $08 / 31 / 2008$ ).

An alternative interpretation of the bank model would be to consider the aggregate banking sector of a country with $\theta$ being a macroeconomic fundamental, with the investors being those outside the banking sector. In this interpretation the ratios are the aggregate ratios, we abstract from any externalities among banks, and a crisis is a crisis of the banking sector.

\section{Equilibrium and strategic complementarity}

In this section we study equilibria of the investors' game and the factors influencing the degree of strategic complementarity. The following proposition provides the equilibrium characterization. The proof is standard and provided in the Appendix for completeness. Let $h_{1}$ denote the smallest slope of $h(\cdot)$ on $(\underset{\sim}{\theta}, \tilde{\theta})$. 
Proposition 1. Let $\gamma \equiv C /(B+C)$.

(i) An equilibrium is characterized by two thresholds $\left(s^{*}, \theta^{*}\right)$ with $s^{*}$ yielding the signal threshold below which an investor acts and $\theta^{*} \in[\underset{\sim}{\theta, \tilde{\theta}}]$ the state-of-the-world critical threshold, below which the acting mass is successful. The probability of a crisis conditional on $s=s^{*}$ is $\gamma$.

(ii) There is a critical $\bar{h}_{0} \in(0,1)$ such that $\theta^{*}=\underset{\sim}{\theta}$ for $h(\underset{\sim}{\theta}) \geq \bar{h}_{0}$, and for $h(\underset{\sim}{\theta})<\bar{h}_{0}$ we have that $\theta^{*}>\underset{\sim}{\theta}$ and then the equilibrium is unique if $\left(\tau_{\theta} / \sqrt{\tau_{\varepsilon}}\right) \leq h_{1} \sqrt{2 \pi}$. If $h(\cdot)$ is linear and $\left(\tau_{\theta} / \sqrt{\tau_{\varepsilon}}\right)>h_{1} \sqrt{2 \pi}$, then there is a range of $\gamma$ for which there are three equilibria.

In order to gain some intuition into the structure of the game and the result let us think in terms of the best reply of a player to the (common) signal threshold used by the other players. Let $P(s, \hat{s})$ be the conditional probability that the acting players succeed if they use a (common) threshold $\hat{s}$ when the player considered receives a signal $s$ (and denote by $\Phi$ the standard Normal cumulative distribution). We have that

$$
P(s, \hat{s}) \equiv \operatorname{Pr}(\theta<\hat{\theta}(\hat{s}) \mid s)=\Phi\left(\sqrt{\tau_{\theta}+\tau_{\varepsilon}}\left(\hat{\theta}(\hat{s})-\frac{\tau_{\theta} \mu_{\theta}+\tau_{\varepsilon} s}{\tau_{\theta}+\tau_{\varepsilon}}\right)\right),
$$

where $\hat{\theta}(\hat{s})$ is the critical $\theta$ below which there is success when players use a strategy with threshold $\hat{s}\left(\hat{\theta}(\hat{s})=\underset{\sim}{\theta}\right.$ if $\Phi\left(\sqrt{\tau_{\varepsilon}}(\hat{s}-\underset{\sim}{\theta})\right) \leq h(\underset{\sim}{\theta})$, otherwise $\hat{\theta}(\hat{s})$ is the solution in $\theta$ of $\Phi\left(\sqrt{\tau_{\varepsilon}}(\hat{s}-\theta)\right)-h(\theta)=0$, which is increasing in $\left.\hat{s}\right)$. It is immediate then that $\partial P / \partial s<0$ and $\partial P / \partial \hat{s} \geq 0$. Given that other players use a strategy with threshold $\hat{s}$, the best response of a player is to use a strategy with threshold $s^{*}$ where $P\left(s^{*}, \hat{s}\right)=\gamma$ : act if and only if $P(s, \hat{s})>\gamma$ or, equivalently, if and only if $s<s^{*}$. This defines a bestresponse function in terms of thresholds

$$
r(\hat{s})=\frac{\tau_{\theta}+\tau_{\varepsilon}}{\tau_{\varepsilon}} \hat{\theta}(\hat{s})-\frac{\tau_{\theta}}{\tau_{\varepsilon}} \mu_{\theta}-\frac{\sqrt{\tau_{\theta}+\tau_{\varepsilon}}}{\tau_{\varepsilon}} \Phi^{-1}(\gamma) .
$$


We have that $r^{\prime}=-(\partial P / \partial \hat{s}) /(\partial P / \partial s) \geq 0$ and the game is, indeed, of strategic complementarities: a higher threshold $\hat{s}$ by others induces a player to use also a higher threshold. It can be shown that if $\left(\tau_{\theta} / \sqrt{\tau_{\varepsilon}}\right) \leq h_{1} \sqrt{2 \pi}$ then $r^{\prime}(\hat{s})=\frac{\tau_{\theta}+\tau_{\varepsilon}}{\tau_{\varepsilon}} \hat{\theta}^{\prime}(\hat{s}) \leq 1$. This ensures that $r(\cdot)$ crosses the $45^{\circ}$ line only once and that the equilibrium is unique. Note that $r^{\prime}$ is increasing in $\tau_{\theta}$ since $\hat{\theta}^{\prime}(\hat{s})$ is independent of $\tau_{\theta}$. A sufficient condition to have multiple equilibria (necessary also for regular equilibria for which $r^{\prime}(\hat{s}) \neq 1$ ) is that $r^{\prime}(s)>1$ for $r(s)=s$.

In consequence, a necessary condition for multiple equilibria is that strategic complementarity be strong enough; a sufficient condition is that strategic complementarity be strong enough at relevant points (candidate equilibria). Indeed, when strategic complementarity is moderate always then there is a unique equilibrium, when it is not there may be multiple equilibria (see Figure 3). When $h(\underset{\sim}{\theta})<\bar{h}_{0}$ and $h_{1}$ is large enough there is a unique equilibrium. In the linear case, for an intermediate range of $\gamma$, as $h_{1}$ decreases we have multiple equilibria (generically three), and if $h_{1}$ decreases further we go back to a unique equilibrium since then strategic complementarity is strong in an irrelevant range (see Figure 3 ). ${ }^{18}$

18 A similar situation arises with movements in $\gamma$, but then the best reply moves vertically (with $\left(\tau_{\theta} / \sqrt{\tau_{\varepsilon}}\right)>h_{1} \sqrt{2 \pi}$, for example, when $h(\theta)=\theta / 10, \quad \tau_{\theta}=1, \quad \tau_{\varepsilon}=5, \quad \bar{\theta}=5 \quad$ and $\gamma \in\{.1, .5, .9\})$. 


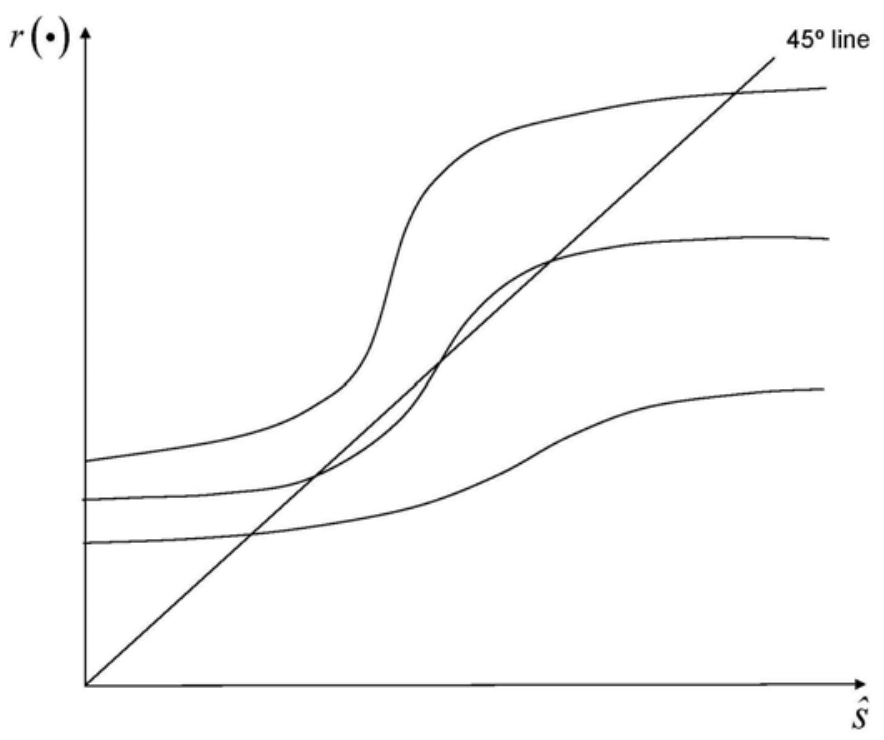

Figure 3: Possible best responses of a player to the threshold strategy $\hat{s}$ used by rivals for an intermediate range of $\gamma$. The lower (upper) branch corresponds to $h_{1}$ high (low), the intermediate to $h_{1}$ intermediate.

The strength of the strategic complementarity among the actions of the players depends on the slope of the best response. The maximal value of the slope is

$$
\bar{r}^{\prime} \equiv \frac{\tau_{\theta}+\tau_{\varepsilon}}{\tau_{\varepsilon}+h_{1} \sqrt{2 \pi \tau_{\varepsilon}}}
$$

which is increasing in $h_{1}^{-1}$ and in $\tau_{\theta}$, and decreasing and then increasing in $\tau_{\varepsilon}$ (with $\bar{r}^{\prime} \rightarrow \infty$ as $\tau_{\varepsilon} \rightarrow 0$ and $\bar{r}^{\prime} \uparrow 1$ as $\left.\tau_{\varepsilon} \rightarrow \infty\right) .{ }^{19}$ Note that $\bar{r}^{\prime} \leq 1$ if and only if $\left(\tau_{\theta} / \sqrt{\tau_{\varepsilon}}\right) \leq h_{1} \sqrt{2 \pi}$. The degree of strategic complementarity will be higher whenever $h$ is less sensitive to $\theta$ (larger $h_{1}^{-1}$ ) and/or the prior is more precise ( $\tau_{\theta}$ large) and/or signals more imprecise $\left(\tau_{\varepsilon}\right.$ low). When $h_{1}^{-1}$ is large a change in fundamentals $\theta$ changes little the critical threshold $h(\theta)$. This implies that a change in the strategy threshold $\hat{s}$ used by other investors leads to a larger optimal reaction since the induced change in the conditional probability that the acting investors succeed is larger. When noise in the

19 It is easily checked that $\operatorname{sign}\left\{\partial \bar{r}^{\prime} / \partial \tau_{\varepsilon}\right\}=\operatorname{sign}\left\{(1 / 2) h_{l} \sqrt{2 \pi \tau_{\varepsilon}}\left(1-\tau_{\theta} \tau_{\varepsilon}^{-1}\right)-\tau_{\theta}\right\}$, in particular $\partial \bar{r}^{\prime} / \partial \tau_{\varepsilon}<0$ for $\tau_{\varepsilon}<\tau_{\theta}$. 
signals is large a player faces little uncertainty about the behavior of others and the strategic complementarity is increased. In the limit cases $\tau_{\varepsilon} \rightarrow+\infty$ (or, equivalently, a diffuse prior $\tau_{\theta} \rightarrow 0$ ), investors face maximal strategic uncertainty (then the distribution of the proportion of acting players $\tilde{y}$ is uniformly distributed over $[0,1]$ conditional on $s_{i}=s^{*}$ ). In contrast, at any of the multiple equilibria with complete information when $\theta \in(\underset{\sim}{\theta}, \tilde{\theta})$, investors face no strategic uncertainty (e.g. in the equilibrium in which everyone acts, an investor has a point belief that all other investors will act).

In the bank runs model maximal strategic complementarity among investors is increasing in $h_{1}^{-1}=\lambda /\left(\ell^{-1}+d^{-1}-m\right)$. That is, strategic complementarity is more likely to be higher with higher short-term leverage $\ell$, face value of short-term debt $d$, or fire sales penalty $\lambda$. Interestingly, strategic complementarity will tend to be higher when the liquidity ratio is higher but recall that if $1-\ell^{-1}-d^{-1}<0$ then $\partial h / \partial m>0$ and a run is less likely to be successful.

\section{Illiquidity risk and insolvency risk}

This section characterizes coordination failure, liquidity and solvency risk, and how they depend on the stress indicators and parameters of the information structure. To do so it develops the comparative statics properties of equilibria, both when the equilibrium is unique or multiple, and works out the implications in the examples considered.

\subsection{Coordination failure, illiquidity risk, and insolvency risk}

At equilibrium with threshold $\theta^{*}$, there is a crisis when $\theta<\theta^{*}$. In the range $\left[\theta^{*}, \tilde{\theta}\right)$ there is coordination failure from the point of view of investors, because if all of them were to act then they would succeed. In the range $\left[\underset{\sim}{\theta}, \theta^{*}\right)$ there is coordination failure from the point of view of the institution attacked. In the bank model in the range $\left[\underset{\sim}{\theta}, \theta^{*}\right)$ the bank 
is solvent but illiquid, that is, the bank would have no problem if only investors would renew their short-term debt, but in the range they do not and the bank is illiquid. ${ }^{20}$

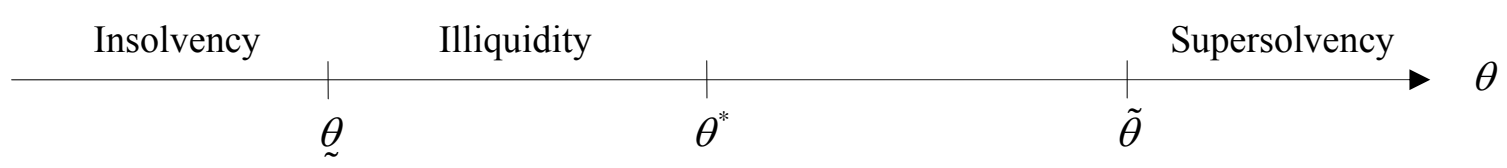

The risk of illiquidity is therefore given by $\operatorname{Pr}\left(\underset{\sim}{\theta} \leq \theta<\theta^{*}\right)$ and the risk of insolvency by $\operatorname{Pr}(\theta<\underset{\sim}{\theta})=\Phi\left(\sqrt{\tau_{\theta}}\left(\underset{\sim}{\theta}-\mu_{\theta}\right)\right)$. The latter is the probability that the bank is insolvent when there is no coordination failure from the point of view of the bank. The overall probability of a "crisis" is $\operatorname{Pr}\left(\theta<\theta^{*}\right)=\Phi\left(\sqrt{\tau_{\theta}}\left(\theta^{*}-\mu_{\theta}\right)\right)$. Note that $\operatorname{Pr}\left(\underset{\sim}{\theta} \leq \theta<\theta^{*}\right)=\operatorname{Pr}\left(\theta<\theta^{*}\right)-\operatorname{Pr}(\theta<\underset{\sim}{\theta})$. A crisis occurs for low values of the fundamentals. In contrast, in the complete information model there are multiple selffulfilling equilibria in the range $(\underset{\sim}{\theta}, \tilde{\theta})$.

\subsection{The comparative statics of risk}

The comparative statics results that follow hold when the equilibrium is unique, and when there are multiple equilibria for the extremal equilibria (the largest and the smallest). Furthermore, the results hold for any equilibrium, even the middle unstable one, if out-of-equilibrium adjustment is adaptive. With best-reply dynamics at any stage after the parameter perturbation from equilibrium, a new state of the world $\theta$ is drawn independently and a player responds to the strategy threshold used by other players at the previous stage. Then a parameter change that moves monotonically the best reply will induce a monotone adjustment process with an unambiguous prediction. For instance, if we are at the higher equilibrium of the middle branch in Figure 3, a decrease in $\alpha$ may induce a movement to the lower branch and best reply dynamics would settle at the

20 As argued by Rochet and Vives (2004) this provides a rationale for a Lender of Last Resort intervention with the discount window. 
unique (and lower) equilibrium. ${ }^{21}$ The following proposition states the results (see the proof in the Appendix).

Proposition 2. Comparative statics. Let $h \underset{\sim}{\theta})<\bar{h}_{0}$. At extremal equilibria (or under adaptive dynamics):

(i) Both $\theta^{*}, s^{*}$ and the probability of crisis $P\left(\theta<\theta^{*}\right)$ are decreasing in $\gamma$ (i.e., with less conservative investors) and in the expected value of the state of the world $\mu_{\theta}$, and increasing in stress indicator $\alpha$.

(ii) A release of a public signal $\mu_{\theta}$ has a multiplier effect on equilibrium thresholds (i.e. over and above the impact on the best response of an investor), which is enhanced if $\tau_{\theta}$ is higher.

(iii) If $\mu_{\theta}$ is low enough (bad times) then a more precise public signal increases $\theta^{*}, P\left(\theta<\theta^{*}\right)$ and the range $\left[\underset{\sim}{\theta}, \theta^{*}\right)$ while a more precise private signal reduces it. If $\mu_{\theta}$ is high enough (good times), the results are reversed.

$\underline{\text { Remark 1: }}$ The range of fundamentals $\left[\underset{\sim}{\theta}, \theta^{*}\right)$ for which there is coordination failure and illiquidity (from the point of view of the institution attacked) is decreasing in $\gamma$ and may increase or decrease with $\alpha$. When $h(\cdot)$ is linear, $\partial h_{0} / \partial \alpha \leq 0$ and $\partial h_{1} / \partial \alpha<0$ (as in the bank model except when $\alpha=m$ ) then the range increases with $\alpha$.

Remark 2: The region of potential multiplicity $\left(\tau_{\theta} / \sqrt{\tau_{\varepsilon}}\right)>h_{1} \sqrt{2 \pi}$ is enlarged with an increase in payoff complementarity (decrease in $h_{1}$ ) and/or an increase in the precision of the public signal in relation to the private one $\tau_{\theta} / \sqrt{\tau_{\varepsilon}}$.

Releasing more public information is not necessarily good according to result (iii). To start with it will not be good if fundamentals are weak ( $\mu_{\theta}$ low enough). In this case a more precise public signal is a coordinating device for investors to act (attack) since each

21 See Echenique (2002) and Vives (2005). 
one knows that others will put more weight to the public signal. The effect is reinforced with a lower precision of private information since then the value of the public signal is enhanced. (Note that strategic complementarity is maximized for high $\tau_{\theta}$ and low $\tau_{\varepsilon}$. .) The opposite happens when fundamentals are good. Furthermore, a public signal, which becomes common knowledge, has the capacity to move the market to a higher threshold equilibrium with a higher probability of a crisis (see Section 7 with the ABX index as a public signal).

\section{Liquidity and solvency regulation of financial intermediaries}

Consider the bank run model where $h(\theta)=m+\lambda^{-1}\left(\ell^{-1}+d^{-1}-m\right)(\theta-\underset{\sim}{\theta})$ with $\underset{\sim}{\theta} \equiv(1-m) /\left(\ell^{-1}+d^{-1}-m\right)$. We present first in the following corollary the comparative static results of risk and deal secondly with regulation.

Corollary 1: In the bank run model there is a critical liquidity ratio $\bar{m} \in(0,1)$ such that for $m<\bar{m}, \theta^{*}>\underset{\sim}{\theta}$ and $\theta^{*}=\underset{\sim}{\theta}$ for $m \geq \bar{m}$. Assume $1-\ell^{-1}-d^{-1}<0$ and $m<\bar{m}$. Then:

- The probability of insolvency $\operatorname{Pr}(\theta<\underset{\sim}{\theta})$ is decreasing in the liquidity ratio $m$ and in the expected return on the bank's assets $\mu_{\theta}$, increasing in the short-term leverage ratio $\ell$ and the face value of debt $d$, and independent of the fire-sales penalty $\lambda$, and the critical withdrawal probability $\gamma$.

- The probability of failure $\operatorname{Pr}\left(\theta<\theta^{*}\right)$ (and the critical $\theta^{*}$ ) and the range of illiquidity $\theta^{*}-\underset{\sim}{\theta}$ are decreasing in $m, \gamma$, and $\mu_{\theta}$, and increasing in $\lambda, \ell$, and $d$. The probability of illiquidity $\operatorname{Pr}\left(\underset{\sim}{\theta} \leq \theta<\theta^{*}\right)$ is decreasing in $\gamma$ and increasing in $\lambda$ and $\ell$.

The limit case where $\tau_{\varepsilon} \rightarrow \infty$ allows for a closed-form solution. Then it is easy to see that

$$
s^{*}=\theta^{*}=\underset{\sim}{\theta}\left(1+\frac{\lambda}{1-m}(\max \{1-\gamma-m, 0\})\right)
$$


and $\bar{m}=1-\gamma .{ }^{22}$ When $m<1-\gamma$, both $\theta^{*}$ and $\theta^{*}-\underset{\sim}{\theta}$ are decreasing in $\gamma$ and in $m$ (provided that $1-\ell^{-1}-d^{-1}<0$ ), and increasing in $\lambda, \ell$, and $d$.

The following table summarizes the results. Note that the qualitative comparative statics of the probability of failure and of the range of illiquidity are identical.

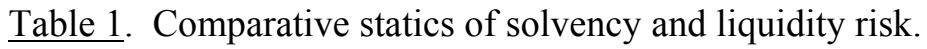

\begin{tabular}{|c|c|c|c|}
\hline & $\operatorname{Pr}(\theta<\underset{\sim}{\theta})$ & $\operatorname{Pr}\left(\theta<\theta^{*}\right)$ & $\theta^{*}-\underset{\sim}{\theta}$ \\
\hline$m$ & $($ Insolvency) & (Failure) & $\begin{array}{r}\text { Range of } \\
\text { illiquidity) }\end{array}$ \\
\hline$\mu_{\theta}$ & $(-)$ & $(-)$ & $(-)$ \\
\hline$\ell$ & $(+)$ & $(-)$ & $(-)$ \\
\hline$d$ & $(+)$ & $(+)$ & $(+)$ \\
\hline$\lambda$ & 0 & $(+)$ & $(+)$ \\
\hline$\gamma$ & 0 & $(+)$ & $(+)$ \\
\hline
\end{tabular}

An increase in balance sheet stress (lower $m$ whenever $1-\ell^{-1}-d^{-1}<0$ or higher $\ell$ ), or market stress (higher $d$, the return of deposits, which can be interpreted as an increase in competitive pressure, or higher $\lambda$, the level of fire-sales penalty for early liquidation, or lower $\gamma$, more conservative investors), increases fragility. Fragility also increases with worse fundamentals (lower $\mu_{\theta}$ ) and more precise public information (higher $\tau_{\theta}$ ) when fundamentals are bad according to Proposition 2. In all the situations with the exception of changes in $\mu_{\theta}$ and $m$ the increase in fragility goes together with an increase in the degree of strategic complementarity. An increase in the liquidity ratio makes an attack

22 Note that in this case $\theta^{*}$ is independent of $\mu_{\theta}$ and $\tau_{\theta}$. 
less likely (whenever $1-\ell^{-1}-d^{-1}<0$ since then $\partial h / \partial m>0$ ) despite that it increases the degree of strategic complementarity.

Let us turn now to regulation in the bank runs model and how the likelihood of crises can be controlled.

Suppose that the regulator wants to control the maximum probabilities of insolvency $q$ and of a crisis $p$, and therefore the probability of illiquidity. This is possible using liquidity and leverage ratios. If the regulator wants that $p=q$ then from Corollary 1 this can be done setting $m \geq \bar{m}$ and inducing $\theta^{*} \underset{\sim}{\theta}$. In general this will be too costly, because of the reduction in the level of investment in the risk asset, and the regulator will set $p>q$.

Since both $\underset{\sim}{\theta}$, and $\theta^{*}$ (where $\theta^{*}$ is the largest equilibrium) are decreasing in $m$ and $\ell^{-1}$, we can make sure that $\operatorname{Pr}(\theta<\underset{\sim}{\theta}) \leq q$ and $\operatorname{Pr}\left(\theta<\theta^{*}\right) \leq p$ choosing $m$ and $\ell^{-1}$ large enough so that

$$
\underset{\sim}{\theta} \leq \underset{\sim}{\theta} \equiv \mu_{\theta}+\Phi^{-1}(q) / \sqrt{\tau_{\theta}},
$$

and

$$
\theta^{*} \leq \theta_{p}^{*} \equiv \mu_{\theta}+\Phi^{-1}(p) / \sqrt{\tau_{\theta}} .
$$

The boundaries of both constraints can de shown to be linear and downward sloping in the space $\left(m, \ell^{-1}\right)$ provided that $1-\ell^{-1}-d^{-1}<0$ :

$$
\ell^{-1} \geq\left(\underset{\sim}{\theta_{q}}\right)^{-1}-d^{-1}-\left(\left({\underset{\sim}{q}}_{q}\right)^{-1}-1\right) m
$$

and

$$
\ell^{-1} \geq \frac{1+k \lambda}{\theta_{p}^{*}}-d^{-1}-\left(\frac{1+\lambda}{\theta_{p}^{*}}-1\right) m .
$$

where $k \in(0,1)$ is a function of $p, \gamma$ and $\tau_{\theta} / \tau_{\varepsilon}$ (see Figure 4). 


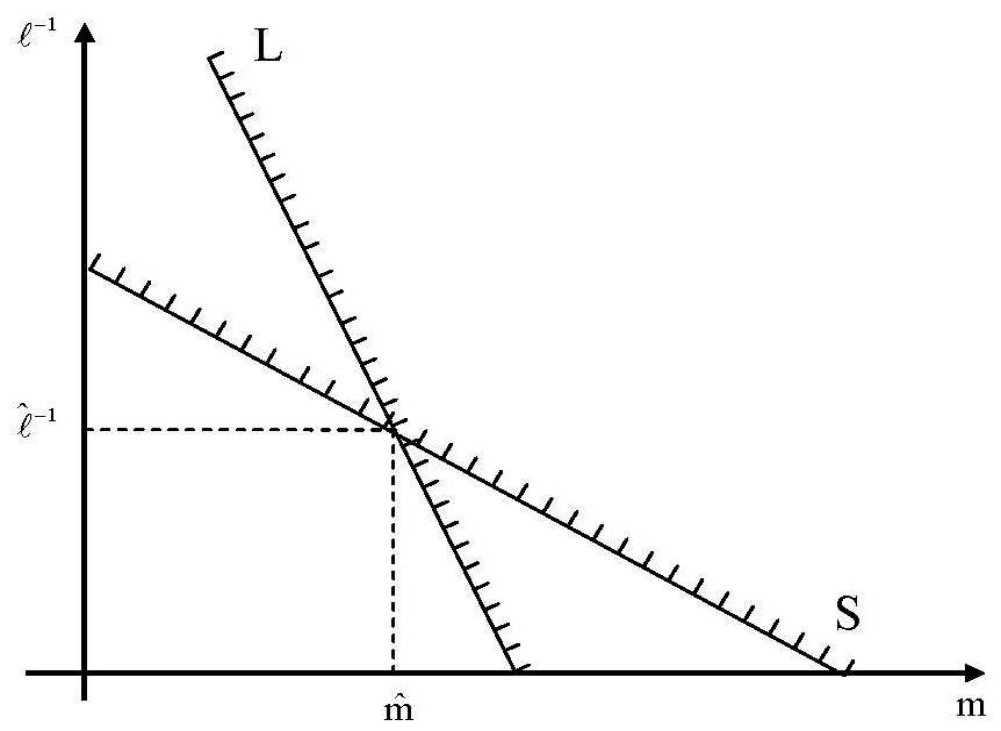

Figure 4: Solvency $(S)$ and liquidity $(L)$ constraints to control probabilities of insolvency and crisis with a short-term leverage ratio $(\ell=D / E)$ and a liquidity ratio $(m=M / D)$.

We have, therefore, that the regulator can control the maximum probabilities of insolvency $q$ and of a crisis $p$, and therefore the probability of illiquidity, by an appropriate induced choice of liquidity $m$ and leverage $\ell$ ratios. The regulator has to propose therefore a region in $\left(m, \ell^{-1}\right)$ space where the ratios of a bank have to lie. This region is limited by a kinked downward sloping schedule reflecting the (partial) substitutability between $m$ and $\ell^{-1}$ (Figure 4). The bank will choose then the least cost combination $\left(m, \ell^{-1}\right)$ which will necessarily lie on the frontier of one of the constraints. It is worth noting that often there will be no loss of efficiency if the regulator sets minimum levels for $\left(m, \ell^{-1}\right)$ given the kink in the constraint set. The minimal $\left(\hat{m}, \hat{\ell}^{-1}\right)$ ratios will be given by the intersection of the boundaries of the solvency and the liquidity constraints. When $\lambda=0$ the two constraints collapse into one and in equilibrium $\theta^{*}=\underset{\sim}{\theta}$. If we require $p=q$, then $\hat{m}=k$ and we can control $q$ with a requirement on $\ell^{-1}$.

The following proposition summarizes the results (see the proof in the Appendix). 
Proposition 3. Let $1-\ell^{-1}-d^{-1}<0$. Then:

(i) To control for the probabilities of insolvency $(q)$ and of a crisis $(p)$ both a solvency (S) and a liquidity (L) constraint -linear and acting on the partially substitutable ratios $\ell^{-1}$ and $m$ - have to be fulfilled. S becomes tighter when $d$ increases and is independent of $\gamma$ and $\lambda$; L becomes tighter when $d, \lambda$ increase or $\gamma$ decreases. Both constraints are more relaxed with higher $\mu_{\theta}$ while (provided $1 / 2>p$ ) higher $\tau_{\theta}$ has a relaxing effect on $\mathrm{S}$ and an ambiguous effect on $\mathrm{L}$.

(ii) There is a constant $k \in(0,1)$ (increasing in $p$, decreasing in $\gamma$, and with ambiguous dependence on $\tau_{\theta} / \tau_{\varepsilon}$ ) such that the minimal regulatory ratios for liquidity and solvency are, respectively, $\hat{m}=\max \left\{1-(1-k)\left(1-\lambda^{-1}\left(\frac{\theta_{p}^{*}}{\theta_{q}}-1\right)\right)^{-1}, 0\right\}$ and $\hat{\ell}^{-1}=\left({\underset{\sim}{q}}_{q}\right)^{-1}-d^{-1}-\left(\left({\underset{\sim}{q}}_{)^{-1}}-1\right) \hat{m}\right.$. If $p>q$ and $\lambda k>\left(\frac{\theta_{p}^{*}}{\theta_{q}}-1\right)$ then $k>\hat{m}>0$ and the comparative statics of the regulatory ratios is given in Table 2. When $\tau_{\varepsilon} \rightarrow \infty$ we have that $k=1-\gamma$.

Table 2. Comparative statics of regulatory ratios when $p>q$, and $\lambda k$ not too small.

\begin{tabular}{|c|c|c|c|c|c|}
\hline & $\lambda$ & $\gamma$ & $d$ & $\mu_{\theta}$ & $\tau_{\theta}$ \\
\hline$\hat{m}$ & $(+)$ & $(-)$ & 0 & $(+)$ & $(+)^{*}$ \\
\hline$\hat{\ell}^{-1}$ & $(-)$ & $(+)$ & $(+)$ & $(-)$ & $(-)^{*}$ \\
\hline
\end{tabular}

*Provided $p<1 / 2$, and either $\tau_{\varepsilon} \rightarrow \infty$ or $\tau_{\varepsilon}$ small enough and $p>\gamma$.

A higher return on short-term debt $d$ will increase the solvency requirement and leave unaffected the liquidity requirement. This is so since both constraints are tightened in a vertical way when $d$ increases (see Figure 5.a). A higher fire sales penalty $\lambda$ and more conservative investment managers (lower $\gamma$ ) will increase the liquidity requirement and decrease the solvency one. This is so since those changes do not affect the solvency 
constraint and tighten the liquidity constraint (see figures 5.b and 5c.). This means that in a more competitive environment (higherd) the solvency requirement has to be strengthened, and in an environment where $\lambda$ is high and $\gamma$ is low the liquidity requirement has to be strengthened while the solvency one relaxed.

An increase in return prospects $\mu_{\theta}$ calls for a higher liquidity requirement and a lower solvency one. Both constraints are more relaxed when $\mu_{\theta}$ increases. However, for $p>q, \quad \theta_{p}^{*} / \theta_{q}$ is decreasing in $\mu_{\theta}$ and therefore $\mathrm{L}$ is relaxed relatively less than $\mathrm{S}$, implying that $\hat{m}$ increases (indeed, $\hat{m}$ is decreasing in $\left.\theta_{p}^{*} / \theta_{q}\right)$ and $\hat{\ell}^{-1}$ decreases with $\mu_{\theta}$ (since $k$ is independent of $\mu_{\theta}$ ). The same is true for an increase in $\tau_{\theta}$ in the case $\tau_{\varepsilon} \rightarrow \infty$ (for which $k=1-\gamma$ ). (See Figure 5.d.) In general, a sufficient condition for $\mathrm{L}$ to be relaxed less than $\mathrm{S}$ (if at all) when $\tau_{\theta}$ increases is that $k$ increases with $\tau_{\theta}$ (and this happens if $\tau_{\varepsilon}$ is small enough and $p>\gamma$ ). Then $\partial \hat{m} / \partial \tau_{\theta}>0$ and $\partial \hat{\ell}^{-1} / \partial \tau_{\theta}<0$. It is also possible that $\partial \hat{m} / \partial \tau_{\theta}<0$ and increasing $\tau_{\theta}$ leads to decreases in both regulatory ratios. ${ }^{23}$

The results imply that the regulator should set together disclosure and prudential policy. It is worth to remark that intermediaries with higher funding costs (higher $d$ ) should have a higher solvency requirement and the same liquidity requirement.

Figure 5.a

${ }^{23}$ For example, when $p=.2, q=.1, \gamma=.29, \lambda=2.1, \mu_{\theta}=d=1.1$, we have that $\partial \hat{m} / \partial \tau_{\theta}<0$ for a wide range of $\tau_{\varepsilon}$ and $\tau_{\theta}$. 


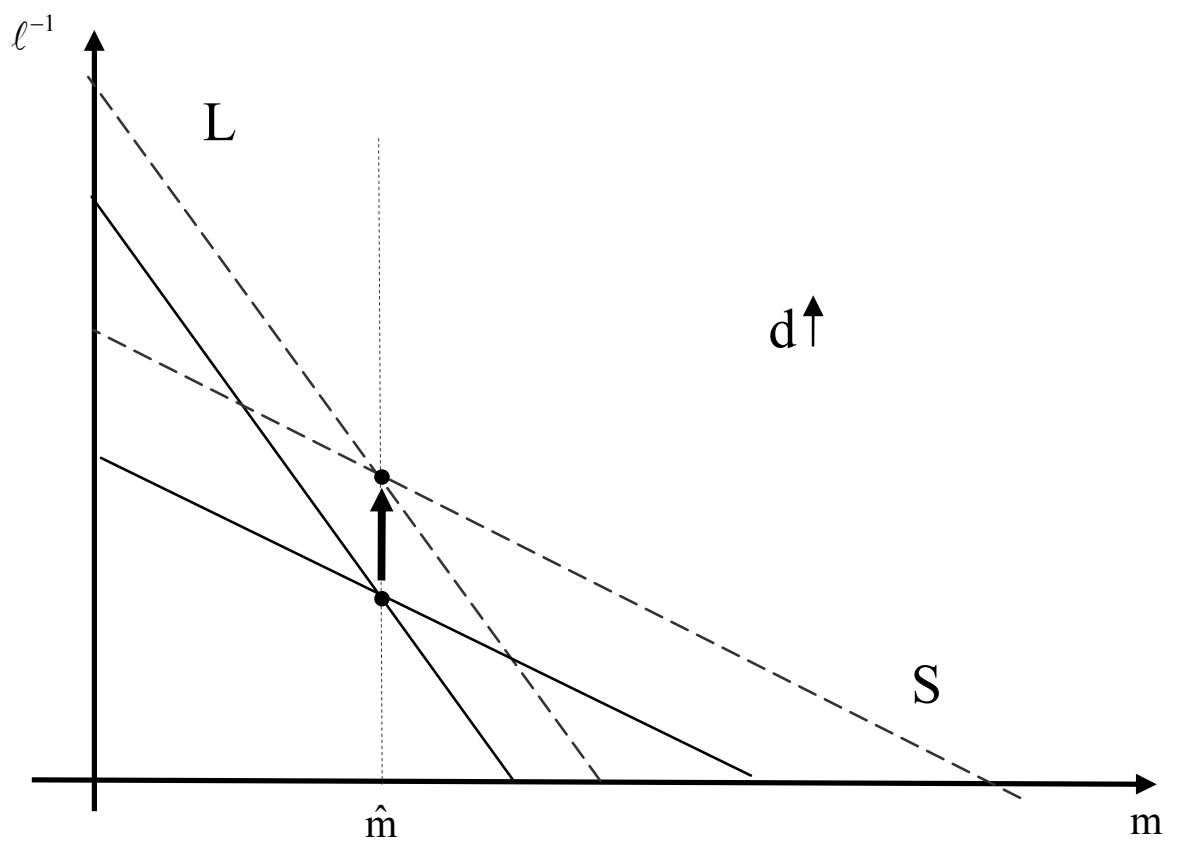

Figure 5.b

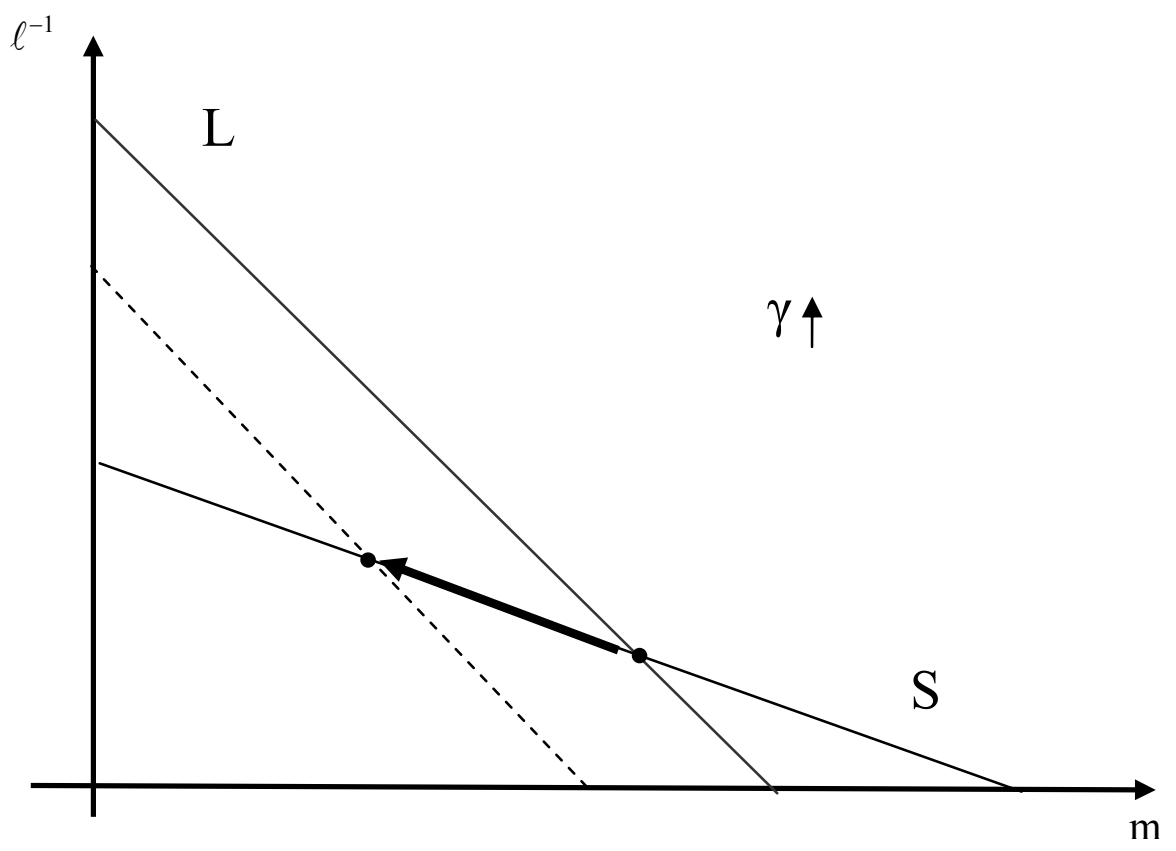

Figure 5.c 


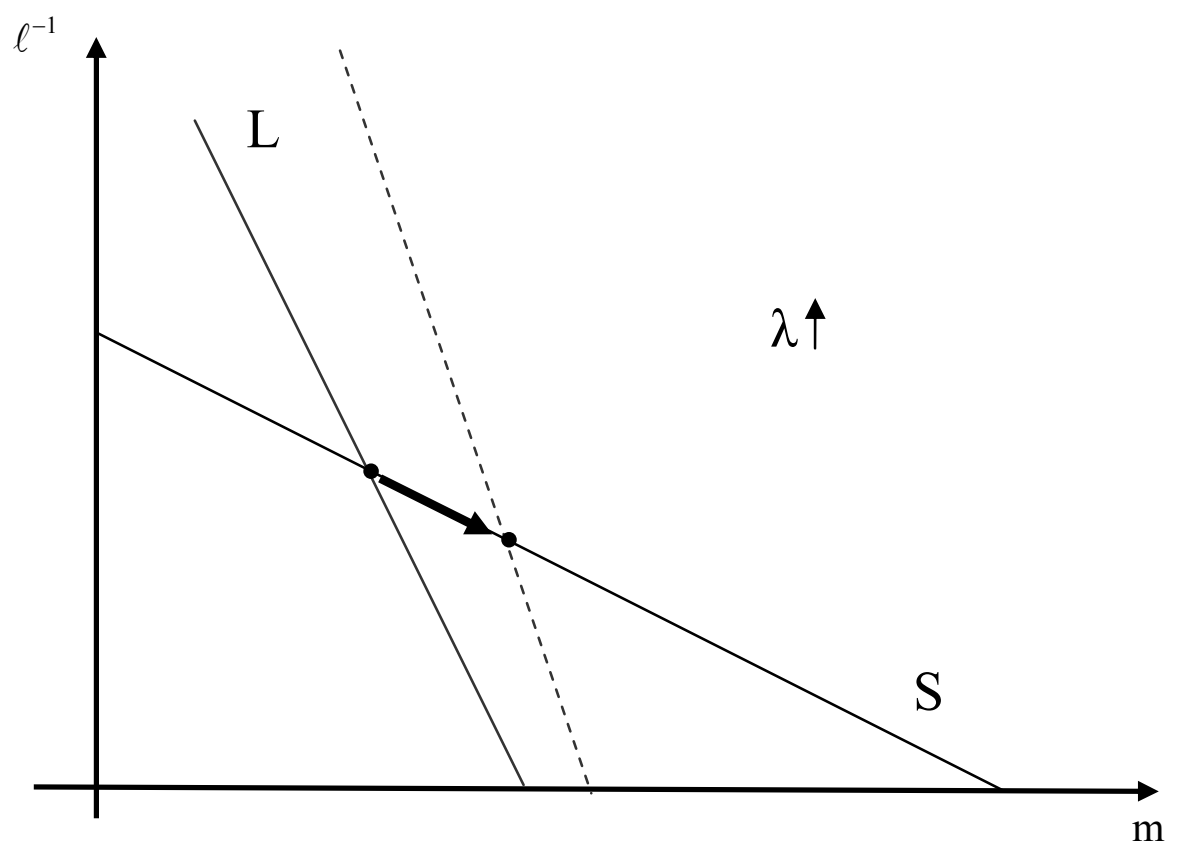

Figure 5.d

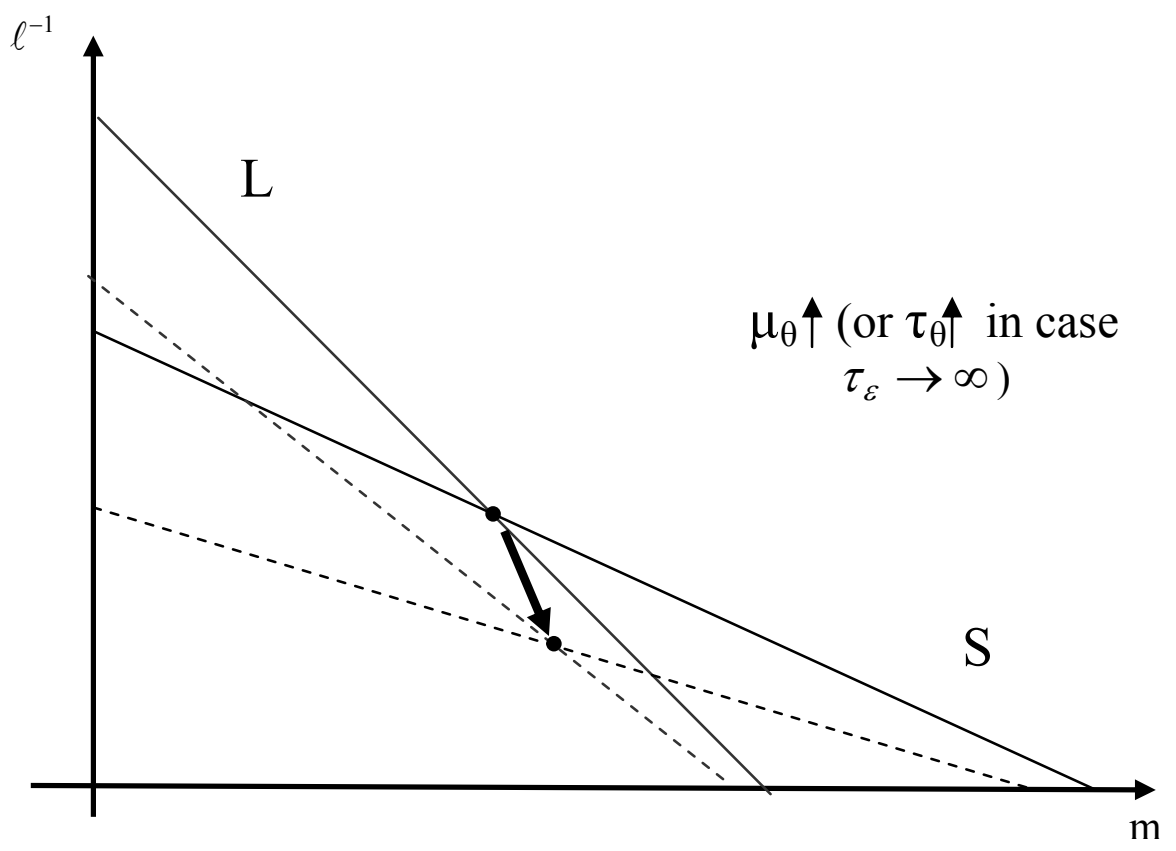




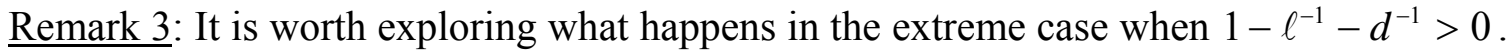
Banks with intense investment banking or wholesale activity have $1-\ell^{-1}>0$, since $\ell=D / E$ is generally above 1 , and therefore $1-\ell^{-1}-d^{-1}>0$ becomes possible. If leverage is high enough, and $1-\ell^{-1}-d^{-1}>0$, then $\partial \underset{\sim}{\theta} / \partial m>0, \underset{\sim}{\theta}>1, \quad$ and $\partial \theta^{*} / \partial m>0$ if $\gamma$ or $\lambda$ are small. In this case increasing the liquidity ratio leads to a higher likelihood of insolvency and crisis. Suppose that the regulator requires that $\underset{\sim}{\theta_{q}}>1$ (assume also that $\left(\underset{\sim}{\theta_{q}}\right)^{-1}-d^{-1}>0$ and $\left.(1+k \lambda)\left(\theta_{p}^{*}\right)^{-1}-d^{-1}>0\right)$. We have then that the solvency constraint is upward sloping, and the liquidity constraint will be also upward sloping if $\theta_{p}^{*}>1+\lambda$. If the liquidity constraint is downward sloping then the potential choices of the bank when faced with the constraints are $\left(m, \ell^{-1}\right)=\left(0,(1+k \lambda)\left(\theta_{p}^{*}\right)^{-1}-d^{-1}\right)$ and $\left(m, \ell^{-1}\right)=\left(\hat{m}, \hat{\ell}^{-1}\right)$. If both constraints are upward sloping then only the first choice survives. This means that when $1-\ell^{-1}-d^{-1}>0$ it may be optimal (to keep the probabilities of insolvency and illiquidity under control) to induce the intermediary to choose to keep no liquid reserves and just impose a leverage limit. In short, for a very highly leveraged institution it is better not to keep liquid reserves.

\section{Literature connections, empirical implications, and evidence}

Previous literature has obtained results related to the ones presented and a growing body of evidence is consistent with them. Let us deal with both issues in turn.

\subsection{Received results}

Chang and Velasco (2001) in a model of financial crisis in emerging markets in the Diamond and Dybvig (1983) tradition find that financial liberalization increases the expected welfare of depositors but may increase also fragility. In Matutes and Vives (1996), in a model which combines the banking model of Diamond (1984) with a differentiated duopolistic structure à la Hotelling, an increase in rivalry does increase the probability of failure in an interior equilibrium of the depositor's game where banks have 
positive market shares. ${ }^{24}$ Cordella and Yeyati (1998) find that disclosure of a risk exposure of a bank (which is not controlled by the bank manager) may increase fragility by increasing the deposit rates demanded by investors. Goldstein and Pauzner (2005) also show how increasing the deposit rate increases the probability of a run of depositors in a model of the global games type.

According to result (iii) in Proposition 2 public information has a coordinating potential beyond its strict information content as in Morris and Shin (2002). Every player knows that an increase in $\mu_{\theta}$ will shift downward the best replies of the rest of the players and everyone will be more cautious in acting. This happens because public information becomes common knowledge and affects the equilibrium outcome. Gala and Volpin (2010) show how public information may be welfare damaging by correlating the investment decisions of agents and exacerbating the negative externality that one borrower imposes on others in the presence of credit rationing.

Morris and Shin (2009) also study how insolvency risk and illiquidity risk vary with the balance sheet composition of a financial institution in a model where future fundamental uncertainty interacts with the strategic uncertainty of the present. In their model there would be no illiquidity risk if there was no future insolvency risk (ex post uncertainty) since it is assumed that partial liquidation of assets has no long run effect. The authors show that illiquidity risk is (i) decreasing in the ratio of cash plus interim realizable assets to short term liabilities; (ii) increasing in the "outside option ratio" (opportunity cost of the funds of short run debt holders); and (iii) increasing in the ex post variance of the asset portfolio ("fundamental risk ratio"). The results and the broad message of the paper are consistent with ours: regulation needs to pay attention to the balance sheet composition of a financial intermediary.

Several negative feedback loops may aggravate a crisis. For example, in the bank crisis model, the fire-sales penalty will be related to adverse selection. Vives (2010) shows how

24 Winton (1997) highlights the role of diversification. 
the asset fire-sale penalty is increasing in the noise in the signals of the bidders and in the amount auctioned, and decreasing in the number of bidders. In a crisis scenario it is plausible to expect noisier signals, an increased amount auctioned, and fewer bidders. All this will mean that when the bank tries to sell more assets because it is in distress it will face a larger discount, and this, in turn, will induce more sales to face the commitments, and further discounts. In the extreme the market may collapse because adverse selection is very severe in relation to the number of bidders. Similar phenomena may happen with the face value of debt since when a bank in distress needs refinancing it will be offered worse terms, and this aggravates in turn the fragility of the bank. ${ }^{25}$

It is worth mentioning also that liquidity requirements may have unintended consequences aggravating adverse selection and drying up markets for liquidity (Malherbe (2011)). The reason is that when intermediaries hoard liquidity their selling behavior is suspicious that they want to get rid of lemon assets. Perotti and Suarez (2011) study how liquidity requirements and Pigouvian taxes can help internalizing the systemic externality induced by the short-term funding of intermediaries.

The presence of large players and market power may introduce further issues. In the interbank market example market power may either facilitate liquidity provision (because liquidity is a public good and then sound banks may have an incentive to provide liquidity to a bank in trouble to avoid contagion (Allen and Gale (2004), Sáez and Shi (2004)) or may impede it (as banks with surplus funds underprovide lending strategically to induce fire-sales of bank-specific assets of needy intermediaries (Acharya et al. $(2010)) \cdot{ }^{26}$

The literature has also found strategic complementarities in the decisions of individual banks that correlate their decisions to force the central bank to bail them out collectively.

25 See Brunnermeier and Pedersen (2009) for a model of a liquidity spiral combining market and funding liquidity, and Bernardo and Welch (2004) for a model where the fear of having to liquidate assets after a crisis may contribute to the frenzy by incentivating sales in the middle of the run. See also Eisenbach (2010) for a feedback model of short-term debt and rollover risk.

26 See also Corsetti et al. $(2004,2006)$ for other effects of the presence of large players. 
Farhi and Tirole (2011) show how private leverage choices of financial intermediaries display strategic complementarities through the response of monetary policy. This makes optimal for banks to adopt a risky balance sheet. Acharya and Yorulmazer (2007) show how the regulator has ex post incentives to bail out failed banks when many fail. This provides incentives to banks, particularly small ones, to herd in their investment policies and increase the risk of collective failure.

\subsection{Empirical implications and evidence}

The model has a rich array of empirical implications. To start with it is a model consistent with crises being driven both by fundamentals and panic components. It predicts also the presence of a multiplier effect of public information, which is increasing in its precision. Table 1 provides testable predictions that link the probability of failure and of insolvency of intermediary with the strength of fundamentals $\left(\mu_{\theta}\right)$, balance sheet ratios ( $m$ and $\ell$ ), and market stress parameters $(\lambda, \gamma$ and $d)$. We have that that the strength of strategic complementarities among investors, with its associated multiplier effect on comparative statics, increases with $\ell, \lambda$ and $d$.

There is evidence that in banking crises are driven by both solvency and liquidity issues. Gorton (1988) in his study of crises in the US National Banking Era (1865-1914) concluded that panics were triggered when the "fundamentals" (a leading indicator of recession) reached a certain level. Calomiris and Mason (2003) find that some episodes of banking crises in the 1930s in the US can be explained by deteriorating fundamentals while others are open to being interpreted as the panic component dominating (as the crises in January and February of 1933). Starr and Yilmaz (2007) study bank runs in Turkey and conclude that both fundamentals and panic elements coexist in the explanation of the dynamics of the crises. Schotter and Yorulmazer (2009) find in an experimental study that the severity of bank runs depends on the fundamentals (the state of the economy).

Identifying and estimating strategic complementarities is not an easy task since the strategic aspect must be disentangled from responses of investors to common shocks. 
Chen et al. (2010) identify strategic complementarities in mutual fund investment by relying precisely on the fact that illiquid funds (those with a higher fire sales penalty $\lambda$ in our model) generate larger strategic complementarities for investors than liquid ones since redemptions impose larger costs in the former funds. Hertzberg et al. (2011)) use a natural experiment with a credit registry expansion in Argentina to identify complementarities.

Consistently with result (ii) in Proposition 2, there is experimental evidence that bank runs occur less frequently when banks face less stress (a lower $\alpha$ in our model) in the sense of a larger number of withdrawals being necessary to induce insolvency (Madies (2006) and Garratt and Keister (2009)). There is also evidence of the multiplier effect of public information (Proposition 2 (iii)) in the credit registry expansion in Argentina (Hertzberg et al. (2011)) and with discount window stigma (Armantier et al. (2011), Acharya and Merrouche (2010)). The latter refers to the reluctance of banks to borrow from the discount window because of fear that the bad news will become publicly known. Armantier et al. (2011) find that during the crisis banks borrowed from the Term Auction Facility, in which the borrowing bank is one of many, at higher rates than those available at the discount window, and that this spread was increasing with more stressed conditions in the interbank market. The spread indicates how much a bank is willing to pay to avoid the release of a public bad signal. This is consistent with the result of having a higher publicity multiplier associated to a higher fire sales penalty $\lambda$ in the interbank market. Consistently with the results in the Corollary 1 among the 72 largest commercial banks in OECD countries, those which relied less on wholesale funding, and had higher capital cushions and liquidity ratios, fared better during the crisis (in the sense of having smaller equity value declines and being subject to less government intervention, see Ratnovski and Huang (2009)). Finally, Fahlenbrach et al. (2011) find that banks with more short term funding performed worse both in the 1998 (as a result of Russia's default on its debt) and in the 2007 crises. 


\section{An interpretation of the 2007 run on SIV}

A slowdown in house prices and tightening of monetary policy led to increasing doubts about subprime mortgages that were reflected in a sharp decline in 2007 in the assetbased securities index ABX. This index had been launched in January 2006 to track the evolution of residential mortgage-based securities (RMBS). The index is a credit derivative based on an equally weighted index of 20 RMBS tranches, and there are also subindexes of tranches with different rating, for different vintages of mortgages. The $\mathrm{ABX}$ index has provided two important functions: information about the aggregate market valuation of subprime risk, and an instrument to cover positions in asset-based securities, for example by shortening the index itself (Gorton $(2008,2009)$ ). ${ }^{27}$ The decline in the ABX index during 2007 seems to have played a major role in the unfolding of the crisis and the run on SIV and ABCP conduits in particular. Indeed, at the end of 2006 sub-indexes for triple-B securities moved somewhat downward after trading at par, and dropped dramatically in 2007 (see Figure 6). ${ }^{28}$ Something similar happened to the $\mathrm{CMBX}$, a synthetic index corresponding to the $\mathrm{ABX}$ including 25 credit default swaps on commercial mortgages.

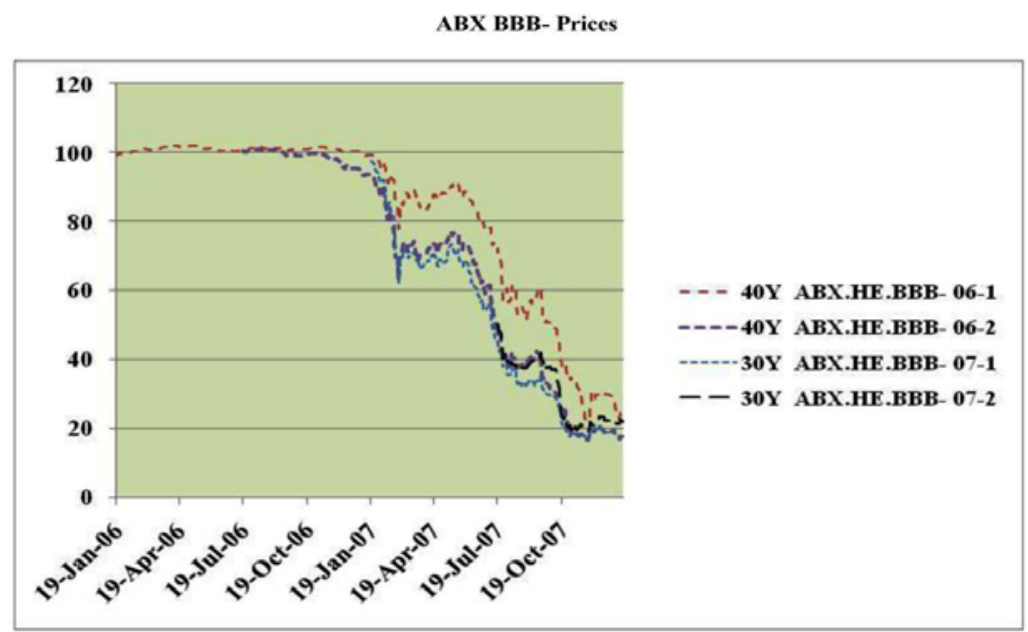

Figure 6: Prices of the 2006-1, 2006-2, 2007-1 and 2007-2 vintages of the ABX index for the BBB- tranche. (Source: Gorton (2008).)

27 In fact, trading in the ABX indices (by Paulson \& Co. and by Goldman Sachs) has delivered two of the largest payouts in the history of financial markets. See Stanton and Wallace (2009) who argue also that ABX prices are imperfect measures of subprime security values.

28 The index starts trading at par except in the case of the 2007-2 index which opened significantly below par. 
These indexes were highly visible and had a strong influence on markets and the evolution of the indexes went together with a sequence of bad news on subprime mortgages (bankruptcies and earning warnings for originators, downgrading of ratings for RMBS bonds and CDO - collateralized debt obligations, and large losses for hedge funds) from January to August 2007. The accumulated bad news in the ABX indexes culminated in the panic of August 2007 when BNP Paribas froze a fund because of a complete evaporation of liquidity in some segments of the US securitized market. A spike in the overnight spread in $\mathrm{ABCP}$ as well as in the Libor-OIS spread followed and the $\mathrm{ABCP}$ outstanding plummeted.

The runs began on ABCP conduits and SIV which had some percentage of securities backed by subprime mortgages. These vehicles were funded with short maturity paper and the run amounted to investors not rolling over the paper. While for a typical SIV, ABCP liabilities were $27 \%$ of the total at the end of 2007 , for a typical conduit they were at $100 \%{ }^{29}$ Those vehicles need not have a high proportion of assets directly contaminated by the subprime mortgages but they had a large indirect exposure through a large share of assets issued by the financial sector. As short-term financing dried up, bank sponsors intervened and absorbed many of these vehicles onto their balance sheets. ${ }^{30}$ It is important to distinguish between the conduits which were motivated by regulatory arbitrage, and which were fully insured by large commercial banks, and those motivated by risk transfer off balance sheet considerations. There is little scope for investor strategic complementarities in the first but substantial in the second. Correspondingly, there was a larger decline in $\mathrm{ABCP}$ conduits of the second type relative to those of the first type starting in August 2007. ${ }^{31}$

Consider the following time line in the basic banking model. At time $t=0$ mortgage loans are awarded and securitized. At $t=0$ a SIV is formed and holds $I$ loans and $M$

29 See the Global Financial Stability Report of the IMF (April 2008).

30 See Acharya and Schnabl (2010) and Covitz et al. (2009) for evidence on the runs in the ABCP market.

31 See Acharya, Schnabl and Suarez (2011). 
reserves financed by equity $E$ and short-term debt $(\mathrm{CDs}) D_{0}$. At $t=1 / 2$ a public signal $p$ about $\theta$ is released. At $t=1$ each fund manager, after receiving a private signal about $\theta$, decides whether to cancel $\left(y_{i}=1\right)$ or renew his $\mathrm{CD}\left(y_{i}=0\right)$. At $t=2$ the returns $\theta I$ on the RMBS assets are collected, if the bank can meet its obligations, the CDs are repaid at their face value $D$, and the equityholders of the SIV obtain the residual (if any).

\begin{tabular}{|c|c|c|c|}
\hline$t=0$ & $t=1 / 2$ & $t=1$ & $t=2$ \\
\hline $\begin{array}{l}\text { SIV formed } \\
\text { with } I \text { RMBS }\end{array}$ & Public signal $P$ released & $\begin{array}{l}\text { Funds managers } \\
\text { receive private } \\
\text { signal and decide } \\
\text { on CD renewal }\end{array}$ & $\begin{array}{l}\theta \text {, return on } \\
\text { RMBS unit } \\
\text { realized }\end{array}$ \\
\hline
\end{tabular}

The public signal $P$ may be the value of the ABX index or the price of a derivatives' market with RMBS as underlying asset. Denote by $\tau$ its precision. In the simplest scenario neither the SIV nor the fund managers in the short-term debt market participate in the derivatives market. In this case the introduction of the ABX index implies a discrete increase in the public precision together with (public) bad news. This will lead to a higher probability of a crisis, a higher $\theta^{*}$, both because of the direct effect of bad news ( $E(\theta \mid P)$ low) and of increased public precision (with $E(\theta \mid P)$ low).

A high level of noise in the signals will push in the same direction also (Proposition 2 (iii)). Recall that a lower $\tau_{\varepsilon}$ increases strategic complementarity when $\tau_{\varepsilon}$ is already low (the maximal slope of $r(\cdot)$ tends to infinity as $\tau_{\varepsilon} \rightarrow 0$ ). Imprecise signals of SIV investors are likely given the opaqueness of the structured subprime products and distance from loan origination. ${ }^{32}$ In this case we may expect $\tau / \sqrt{\tau_{\varepsilon}}$ to be large also. The reason is that the precision of the signal of the fund managers (investors in the SIV) $\tau_{\varepsilon}$

32 See Pagano and Volpin (2009) for a model where issuers of structured bonds choose opaque ratings to enhance the liquidity of their primary market at the cost of diminishing (perhaps drastically) the liquidity of the secondary market. Wagner (2007) argues that financial development may incentivate banks to move into more opaque assets. 
may be low (think of the German Landesbank investing in structured subprime products) and much lower than the precision of the private signals of the sophisticated traders in the derivatives market (think of investment banks such as Goldman Sachs or hedge funds such as Paulson\&Co) which influence positively the public precision $\tau$ (together with their risk tolerance). ${ }^{33}$

The impact of the bad news is magnified when short-term leverage $\ell$, the cost of funds $d$, and fire sales penalty $\lambda$ for early asset sales are high (all those factors make $h_{1}^{-1}$ and strategic complementarity high). This was the situation in the crisis. In fact, the fire-sale penalties increased dramatically with the market becoming practically illiquid. Those SIV then had to be absorbed back by the parent banking institution. It is worth noting also that, according to Proposition 3 and Table 2, when $\tau_{\varepsilon}$ is low and investors are conservative (with $\gamma<p$ ) a higher precision of the public signal should lead to an increased liquidity requirement. That is, when the assets are opaque the introduction of a strong public signal like the one provided in a derivatives market should be accompanied with a tightened liquidity obligation.

The presence of a derivative market may have other consequences. First of all, it may allow hedging the risk associated to the subprime products. This can be done by the SIV itself, by the fund managers with exposure to SIV by providing short-term financing, and by other investors with subprime exposure. ${ }^{34}$ The SIV by shorting the index may reduce exposure to subprime risk and increase reserves for potential non-renewal of CDs at $t=1$ at the cost of not profiting from the full appreciation potential of the subprime investment $I$. If the SIV hedges completely its position then it is completely safe but the expected return is low, a partial hedge will increase the reserves to diminish the failure

33 See Angeletos and Werning (2006), Tarashev (2007), and Vives (Section 4.4, 2008) for related models.

34 Public precision of the price in the derivatives market will decrease in the degree of risk aversion of informed investors in the market and in the sensitivity of the hedger demand to their endowment shock (Vives (Section 4.4, 2008)). 
probability. Interestingly, the private information of the SIV hurts its hedging possibilities creating adverse selection in the derivatives market. 35

\section{Other applications}

We deal in this section with two more illustrations of our approach: a currency attack model and a credit freezes model.

Currency attacks. A streamlined version of the currency attacks model of Morris and Shin (1998) where $\theta$ represents the reserves of the central bank (with $\theta \leq 0$ meaning that reserves are depleted) fits our general model. Each speculator has one unit of resources to attack the currency $\left(y_{i}=1\right)$ at a cost $C$. Letting $h(\theta ; \alpha)=\alpha^{-1} \theta$, where $\alpha>0$ is the mass of attackers or $\alpha^{-1}$ the proportion of uncommitted reserves of the central bank, the attack succeeds if $y \geq \alpha^{-1} \theta$. Still $\alpha$ could be interpreted as the wealth available to a fixed mass of speculators. (See Figure 7a.) The capital gain if there is depreciation is fixed and equal to $\hat{B}=B+C$. We have that $\gamma \equiv C /(B+C)$ is likely to be small.

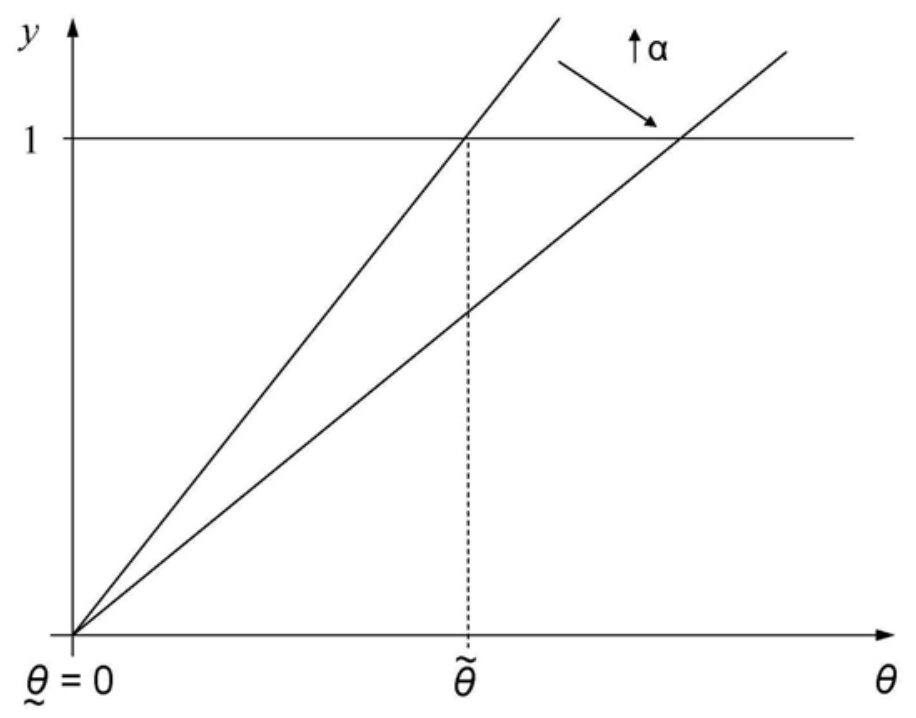

35 When the SIV has market power and precise information in relation to the prior, and the hedgers have a endowment shocks very correlated then the derivatives market dries up (Medrano and Vives (2004)). This is likely to be the case in a crisis situation. 
Figure 7a. The function $h(\theta ; \alpha)=\alpha^{-1} \theta$ in the currency crises model.

In the range $\left[\theta^{*}, \tilde{\theta}\right)$ if currency speculators were to coordinate their attack then they would succeed, but in fact the currency holds. From Proposition 2 (i) we have immediately that the probability of a currency crisis is decreasing in the relative cost of the attack $\gamma$ and in the expected value of the reserves of the central bank $\mu_{\theta}$; the probability of illiquidity $\operatorname{Pr}\left(\underset{\sim}{\theta} \leq \theta<\theta^{*}\right)$ increases with $\alpha$ while the probability of insolvency $\operatorname{Pr}(\theta<\underset{\sim}{\theta})$ is unaffected by $\alpha \cdot{ }^{36}$

Credit market freezes. Consider the model of self-fulfilling freezes in credit markets of Bebchuk and Goldstein (2011). This is a variation of the loan foreclosure model by Morris and Shin (2004)). ${ }^{37}$ In this case $\theta$ are the fundamentals of the firms and $y$ the proportion of banks not renewing credit to firms. Firms with good projects, at which banks can invest, have a return above the risk-free rate only if $\theta \geq \underset{\sim}{\theta}(\alpha)+\alpha^{-1} y$ where $\underset{\sim}{\theta}(\alpha)=\tilde{\theta}-\alpha^{-1}$ with $\tilde{\theta}>0$. Firms with bad projects return noting and banks can detect good projects from bad ones. The parameter $\alpha$ is to be interpreted as the inverse of the product of the mass of banks and a complementarity parameter that explains the performance of firms. We have that $h(\theta ; \alpha)=\alpha(\theta-\underset{\sim}{\theta}(\alpha))$ (see Figure 7b.) Note that in this case the increase in fragility, $\partial h / \partial \alpha=-\tilde{\theta}<0$, goes together with a decrease in the degree of strategic complementarity, $\partial h_{1} / \partial \alpha>0$. The parameter $1-\gamma$ equals the

36 When $h(\theta)=\alpha^{-1} \theta$ we have always that $\underset{\sim}{\theta}<\theta^{*}$ and $\operatorname{Pr}\left(\underset{\sim}{\theta} \leq \theta<\theta^{*}\right)$ increases with $\alpha \quad(\underset{\sim}{\theta}=0$ and $\theta^{*}$ increases with $\alpha$ ).

37 The loan foreclosure model is formally equivalent to the currency attacks model. Now $\theta$ is the ability of the firm to meet short-term claims (where $\theta \leq 0$ means no ability). The action is to foreclose a loan. In this case $h(\theta ; \alpha)=\alpha^{-1} \theta$ where $\alpha>0$ is the mass of creditors (or $\alpha^{-1}$ proportion of uncommitted liquid resources of the firm) and the project fails if $y \geq \alpha^{-1} \theta$. The face value of the loan is $L$, the value of collateral (at interim liquidation) is $K<L$ and let $B=K$ and $C=L-K$. We have that $\gamma \equiv 1-K / L$. 
ratio of the gross risk-free return to the gross return of good projects. The authors use the model to assess the responses of the government in the present financial crisis. The comparative static results in Proposition 2 apply.

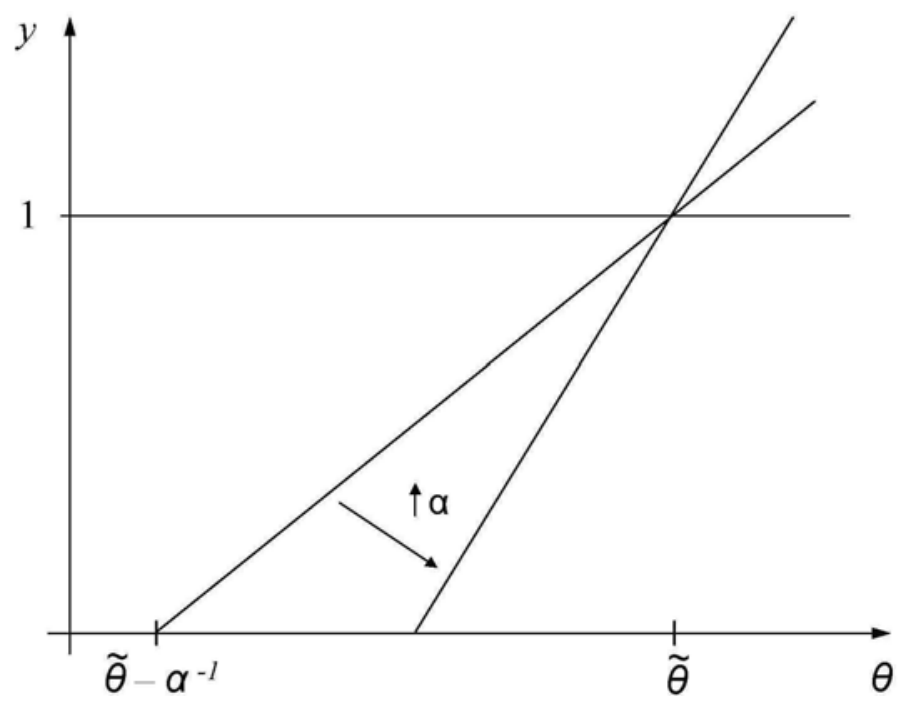

Figure $7 \mathrm{~b}$. The function $h(\theta ; \alpha)=\alpha(\theta-\underset{\sim}{\theta}(\alpha))$ in the credit market freezes model.

\section{Concluding remarks}

This paper presents a stylized model of a financial crisis which characterizes solvency and liquidity risk and highlights how the degree of strategic complementarity among actions of investors is a key parameter to understand fragility. The results characterize how market outcomes depend on the balance sheet structure (leverage and liquidity), market stress parameters (degree of competition, the fire sales penalty of early liquidation of investments), and the informativeness of public and private signals. Fragility increases with balance sheet stress (short-term leverage, low liquidity, high return on short-term debt); with market stress (fire sales penalty, more conservative investors), and with the precision of public information when fundamentals are weak. A high degree of opaqueness on the asset side of a financial intermediary together with a strong public signal (say from a derivatives market) will increase the degree of strategic complementarity and potential fragility. 
The main general policy conclusion on regulatory reform is that a piecemeal approach will not work. The regulator will need to pay attention to the composition of the balance sheet of a financial intermediary and to the level of disclosure to control the probabilities of insolvency and illiquidity. In order to do so a leverage limitation and a liquidity requirement are needed, they are partially substitutable, and have to be set together taking into account the level of transparency. Indeed, in an environment with high market illiquidity and conservative investors the liquidity requirement has to be tightened while the solvency one relaxed; prudential constraints may have to be modified with higher disclosure levels (e.g. with stricter liquidity and relaxed solvency requirements). Competition policy and prudential regulation are not independent: In a more competitive situation leverage limits have to be strengthened. ${ }^{38}$

The analysis has several important limitations. First of all, the balance sheet of the intermediary is exogenous and, correspondingly, the objectives of the regulator are also exogenous. Both could be endogenized introducing, for example, a moral hazard o commitment problem on the part of the intermediary which would rationalize the shortterm debt structure and indicate an optimal closure policy for the regulator. ${ }^{39}$ Second, the analysis is basically static while we are trying to capture dynamic phenomena. ${ }^{40}$ Third, the investors are symmetric ${ }^{41}$; and finally, the analysis focuses on a single institution or a consolidated banking sector and takes market parameters as given (e.g., the fire sales penalty); consequently, it does not take into account externalities among banks and systemic effects. ${ }^{42}$ These issues are left for further research.

\footnotetext{
38 This theme is developed in Vives (2011).

39 See Calomiris and Kahn (1991), Diamond and Rajan (2000), Gale and Vives (2002) and Rochet and Vives (2004) for related approaches to the issue.

40 See, for example, the dynamic analysis of panic debt runs in He and Xiong (2009).

41 Steiner and Sákovics (2009) study a global game example where players are ex ante asymmetric.

42 See Acharya and Yorulmazer (2007) and Farhi and Tirole (2011).
} 


\section{Appendix}

Proof of Proposition 1: The game is "monotone supermodular" (i.e., of strategic complementarities with a monotone information structure) since $\pi\left(y_{i}, y ; \theta\right)$ has increasing differences in $\left(y_{i},(y,-\theta)\right)$, that is, the differential payoff to act $\pi^{1}-\pi^{0}$ is increasing in the aggregate action and the negative of the state of the world $(y,-\theta)$, and signals are affiliated. This means that extremal equilibria exist, are symmetric (because the game is symmetric), and are in monotone (decreasing) strategies in type (Van Zandt and Vives (2007)). Since there are only two possible actions, the strategies must then be of the threshold form: $y_{i}=1$ if and only if $s_{i}<\hat{s}$ where $\hat{s}$ is the threshold. It follows also that the extremal equilibrium thresholds, denoted $\bar{s}$ and $\underline{s}$, bound the set of strategies which are the outcome of iterated elimination of strictly dominated strategies. If $\bar{s}=\underline{s}$ the game is dominance solvable and the equilibrium is unique. An equilibrium will be characterized by two thresholds $\left(s^{*}, \theta^{*}\right)$ with $s^{*}$ yielding the signal threshold to act and $\theta^{*}$ the state-of-the-world critical threshold, below which the acting mass is successful and an acting player obtains the payoff $B-C>0$. In equilibrium the fraction of acting players $y\left(\theta^{*}, s^{*}\right)=\operatorname{Pr}\left(s \leq s^{*} \mid \theta^{*}\right) \equiv \Phi\left(\sqrt{\tau_{\varepsilon}}\left(s^{*}-\theta^{*}\right)\right)$ must be no larger than the critical fraction above which it pays to act $h\left(\theta^{*}\right)$. Note that $\theta^{*} \in[\underset{\sim}{\theta}, \tilde{\theta}]$ since $\lim _{\theta \uparrow \hat{\vartheta}} h(\theta)=0$ and $h(\tilde{\theta})=1$. Furthermore, at the critical signal threshold the expected payoff of acting and not acting should be the same:

$$
\begin{aligned}
& E\left[\pi(1, y(\theta, s) ; \theta)-\pi(0, y(\theta, s) ; \theta) \mid s=s^{*}\right] \\
= & \operatorname{Pr}\left(\theta \leq \theta^{*} \mid s^{*}\right) B+\operatorname{Pr}\left(\theta>\theta^{*} \mid s^{*}\right)(-C)=0 ;
\end{aligned}
$$

or $\operatorname{Pr}\left(\theta \leq \theta^{*} \mid s^{*}\right) \equiv \Phi\left(\sqrt{\tau_{\theta}+\tau_{\varepsilon}}\left(\theta^{*}-\frac{\tau_{\theta} \mu_{\theta}+\tau_{\varepsilon} s^{*}}{\tau_{\theta}+\tau_{\varepsilon}}\right)\right)=\gamma$, where $\gamma \equiv C /(B+C)<1$.

If $\Phi\left(\sqrt{\tau_{\varepsilon}}\left(s^{*}-\underset{\sim}{\theta}\right)\right) \leq h(\underset{\sim}{\theta})$ then $\theta^{*}=\underset{\sim}{\theta}$. Otherwise, $\Phi\left(\sqrt{\tau_{\varepsilon}}\left(s^{*}-\theta^{*}\right)\right)=h\left(\theta^{*}\right)$ and $\theta^{*}>\underset{\sim}{\theta}$. There is a critical $\bar{h}_{0} \in(0,1)$ such that for $h(\underset{\sim}{\theta})<\bar{h}_{0}$ we have that $\theta^{*}>\underset{\sim}{\theta}$ and $\theta^{*}=\underset{\sim}{\theta}$ for $h(\underset{\sim}{\theta}) \geq \overline{h_{0}}$. Since $\theta^{*}=\underset{\sim}{\theta}$ when $s^{*} \leq \underset{\sim}{\theta}+\Phi^{-1}(h(\underset{\sim}{\theta})) / \sqrt{\tau_{\varepsilon}}$ and by 
replacing $s^{*}=\underset{\sim}{\theta}+\Phi^{-1}(h(\underset{\sim}{\theta})) / \sqrt{\tau_{\varepsilon}}$ in $\Phi\left(\sqrt{\tau_{\theta}+\tau_{\varepsilon}}\left(\theta^{*}-\frac{\tau_{\theta} \mu_{\theta}+\tau_{\varepsilon} s^{*}}{\tau_{\theta}+\tau_{\varepsilon}}\right)\right)=\gamma$, it follows that $\bar{h}_{0}=\Phi\left(\frac{\tau_{\theta}}{\sqrt{\tau_{\varepsilon}}}\left(\underset{\sim}{\theta}-\mu_{\theta}\right)-\sqrt{1+\frac{\tau_{\theta}}{\tau_{\varepsilon}}} \Phi^{-1}(\gamma)\right)$. Let $h(\underset{\sim}{\theta})<\bar{h}_{0}$, then equations $\Phi\left(\sqrt{\tau_{\varepsilon}}\left(s^{*}-\theta^{*}\right)\right)=h\left(\theta^{*}\right)$ and (2) $\Phi\left(\sqrt{\tau_{\theta}+\tau_{\varepsilon}}\left(\theta^{*}-\frac{\tau_{\theta} \mu_{\theta}+\tau_{\varepsilon} s^{*}}{\tau_{\theta}+\tau_{\varepsilon}}\right)\right)=\gamma$ combine into equation

$$
\varphi\left(\theta^{*}\right) \equiv \tau_{\theta}\left(\theta^{*}-\mu_{\theta}\right)-\sqrt{\tau_{\varepsilon}} \Phi^{-1}\left(h\left(\theta^{*}\right)\right)-\sqrt{\tau_{\theta}+\tau_{\varepsilon}} \Phi^{-1}(\gamma)=0,
$$

by substituting the value of $s^{*}$ from (1) into (2). This equation may have multiple solutions in $\theta^{*}$. As $\theta \rightarrow \tilde{\theta}$ we have that $\Phi^{-1}(h(\theta))$ tends to $+\infty$ and $\varphi \rightarrow-\infty$; as $\theta \rightarrow \underset{\sim}{\theta}$ we have that $h(\theta) \rightarrow h(\underset{\sim}{\theta})$ and $\varphi \rightarrow \varphi(\underset{\sim}{\theta})>0$ whenever $h(\underset{\sim}{\theta})<\bar{h}_{0}$. There is at least a solution $\theta^{*} \in[\underset{\sim}{\theta}, \tilde{\theta}]$. The solution will be unique if $\varphi^{\prime}<0$; there will be multiple solutions if $\varphi^{\prime}(\theta)>0$ for a potential solution $\varphi(\theta)=0$ (three in fact when $h(\cdot)$ is linear, and two when there is a $\theta$ such that $\varphi(\theta)=0$ and $\varphi^{\prime}(\theta)=0$.). As $\gamma$ tends to 0 (1) we have that $\Phi^{-1}(\gamma)$ tends to $-\infty(+\infty), s^{*}$ tends to (minus) infinity and $\theta^{*}$ tends to $\tilde{\theta}(\underset{\sim}{\theta})$. This follows from equation (2) and the fact that $\theta^{*} \in[\underset{\sim}{\theta}, \tilde{\theta}]$. There is a unique solution if $\tau_{\theta} / \sqrt{\tau_{\varepsilon}} \leq h_{1} \sqrt{2 \pi}$. Indeed, $\varphi^{\prime}=1-\left(\sqrt{\tau_{\varepsilon}} / \tau_{\theta}\right) h^{\prime}\left[\phi\left(\Phi^{-1}(h(\theta))\right)\right]^{-1}$, where $\phi$ is the density of the standard normal. Since $\phi$ is bounded above by $1 / \sqrt{2 \pi}$ and $h_{1}$ is the smallest slope of $h(\cdot)$, it follows that $\varphi^{\prime}$ is bounded above: $\varphi^{\prime} \leq 1-h_{1} \sqrt{2 \pi \tau_{\varepsilon}} / \tau_{\theta}$ (with strict inequality, except possibly when $h(\theta)=1 / 2$ because then $\Phi^{-1}(1 / 2)=0$ and $\phi$ attains its maximum: $\left.\phi(0)=1 / \sqrt{2 \pi}\right)$. Therefore, if $\tau_{\theta} / \sqrt{\tau_{\varepsilon}} \leq h_{1} \sqrt{2 \pi}$ then $\varphi^{\prime} \leq 0$. In this case the equilibrium is unique and the game is dominance solvable because then $\bar{s}=\underline{s}$. Furthermore, it should be clear that the critical thresholds $\theta^{*}$ and $s^{*}$ move together. Suppose $h(\cdot)$ is linear, then if $\tau_{\theta} / \sqrt{\tau_{\varepsilon}}>h_{1} \sqrt{2 \pi}$ there is a range of $\gamma$ for which there are multiple equilibria. Indeed, choose $\gamma$ such that $h\left(\theta^{*}\right)=1 / 2$, then $\varphi^{\prime}\left(\theta^{*}\right)>0$ and there must be three equilibria, 
and by continuity there is a neighborhood of such $\gamma$ with multiple equilibria. Note that for $\gamma$ small we will have a unique equilibrium (high) and for $\gamma$ high a unique equilibrium (low) since as $\gamma$ tends to $0(1)$ we have that $\Phi^{-1}(\gamma)$ tends to $-\infty(+\infty)$ and $\varphi$ to $+\infty$ $(-\infty)$ for any given $\theta^{*} \in(\underset{\sim}{\theta}, \tilde{\theta})$. Given the shape of $\varphi$ (decreasing-increasingdecreasing) for $\gamma$ small we obtain an equilibrium in the third decreasing portion and for $\gamma$ high an equilibrium in the first decreasing portion.

Claim 1: If $\left(\tau_{\theta} / \sqrt{\tau_{\varepsilon}}\right) \leq h_{1} \sqrt{2 \pi}$ then $r^{\prime}(\hat{s})=\frac{\tau_{\theta}+\tau_{\varepsilon}}{\tau_{\varepsilon}} \hat{\theta}^{\prime}(\hat{s}) \leq 1$.

Proof: From the equation $\Phi\left(\sqrt{\tau_{\varepsilon}}(\hat{s}-\theta)\right)=h(\theta)$ we can solve for $\hat{s}$ as a function of $\theta$ and obtain $\hat{s}(\theta)=\theta+\left(1 / \sqrt{\tau_{\varepsilon}}\right) \Phi^{-1}(h(\theta)) \quad$ with derivative $\hat{s}^{\prime}=1+\left(1 / \sqrt{\tau_{\varepsilon}}\right) h^{\prime}\left(\phi\left(\Phi^{-1}(h(\theta))\right)\right)^{-1}$, where $\phi$ is the density of the standard normal. Since $\phi$ is bounded above by $1 / \sqrt{2 \pi}$ and $h_{1}$ is the smallest slope of $h(\cdot)$, it follows that $\hat{s}^{\prime}$ is bounded below: $\hat{s}^{\prime} \geq 1+\sqrt{2 \pi / \tau_{\varepsilon}} h_{1}$. Hence, $\hat{\theta}^{\prime}(\hat{s}) \leq\left(1+\sqrt{2 \pi / \tau_{\varepsilon}} h_{1}\right)^{-1}$, with strict inequality, except possibly when $h(\theta)=1 / 2$ because then $\Phi^{-1}(1 / 2)=0$ and $\phi$ attains its maximum: $\phi(0)=1 / \sqrt{2 \pi}$.

Proof of Proposition 2: When $h(\underset{\sim}{\theta})<\bar{h}_{0}$, the equation

$$
\varphi\left(\theta^{*}\right) \equiv \tau_{\theta}\left(\theta^{*}-\mu_{\theta}\right)-\sqrt{\tau_{\varepsilon}} \Phi^{-1}\left(h\left(\theta^{*}\right)\right)-\sqrt{\tau_{\theta}+\tau_{\varepsilon}} \Phi^{-1}(\gamma)=0
$$

determines $\theta^{*}$. We obtain the results by looking at how parameter changes impinge on $\varphi(\cdot)$. When $\tau_{\theta} / \sqrt{\tau_{\varepsilon}} \leq h_{1} \sqrt{2 \pi}$, we have that $\varphi^{\prime}<0$ and there is a unique equilibrium. The usual comparative static analysis applies. When $\tau_{\theta} / \sqrt{\tau_{\varepsilon}}>h_{1} \sqrt{2 \pi}$ there may be multiple equilibria and the results will apply to the extremal ones. With adaptive dynamics the results apply in general. 
(i) The result for $\theta^{*}$ follows since $\varphi$ is decreasing in $\gamma$ and $\mu_{\theta}$, and increasing in $\alpha$ since $\partial h / \partial \alpha<0$. The threshold $s^{*}$ moves with $\theta^{*} .{ }^{43}$ The result for $P\left(\theta<\theta^{*}\right)$ is immediate for $\gamma$ and $\alpha$, and for $\mu_{\theta}$ also since increases in $\mu_{\theta}$ move the distribution of $\theta$ to the right. (ii) Suppose the equilibrium is unique. The equilibrium signal threshold is determined by $r\left(s^{*} ; \mu_{\theta}\right)-s^{*}=0$. From which it follows that for a marginal change in $\mu_{\theta}$

$$
\left|\frac{d s^{*}}{d \mu_{\theta}}\right|=\frac{\left|\partial r / \partial \mu_{\theta}\right|}{1-r^{\prime}}>\left|\frac{\partial r}{\partial \mu_{\theta}}\right|
$$

whenever $r^{\prime}<1$ is met and $r^{\prime}>0$. In consequence, an increase in $\mu_{\theta}$ will have a larger effect on the equilibrium threshold $s^{*}$ than the direct impact on the best response of a player $\partial r / \partial \mu_{\theta}=-\tau_{\theta} / \tau_{\epsilon}$. The same is true for discrete changes even with multiple equilibria if we restrict attention to extremal equilibria or in general with adaptive dynamics. This multiplier effect is largest when $r^{\prime}$ is close to 1 at equilibrium, that is, when strategic complementarities are strong, and we approach the region of multiplicity of equilibria. This is so when $\tau_{\theta}$ is large since $r^{\prime}$ is increasing in $\tau_{\theta}$. (iii) Let $\theta^{*}$ be the smallest equilibrium. The first part follows since $\partial \varphi / \partial \tau_{\theta}=\theta^{*}-\mu_{\theta}-\left(\tau_{\theta}+\tau_{\varepsilon}\right)^{-1 / 2} \Phi^{-1}(\gamma) / 2 \quad$ and therefore $\partial \varphi / \partial \tau_{\theta}>0 \quad$ if $\theta^{*}>\mu_{\theta}+\left(\tau_{\theta}+\tau_{\varepsilon}\right)^{-1 / 2} \Phi^{-1}(\gamma) / 2$. Note that $\theta^{*}$ is decreasing in $\mu_{\theta}$ and therefore for low enough $\mu_{\theta}$ (recall that $\mu_{\theta}$ can be negative when interpreted as a public signal) we will have that $\theta^{*}>\mu_{\theta}$. Note that if $\theta^{*}>\mu_{\theta}$ when $\tau_{\theta}$ increases $\operatorname{Pr}\left(\theta<\theta^{*}\right)=\Phi\left(\sqrt{\tau_{\theta}}\left(\theta^{*}-\mu_{\theta}\right)\right)$ also increases. For the second part, using the equation $\varphi\left(\theta^{*}\right)=0$ in $\partial \varphi / \partial \tau_{\varepsilon}$ we obtain $\partial \varphi / \partial \tau_{\varepsilon}=-\left(\theta^{*}-\mu_{\theta}-\left(\tau_{\theta}+\tau_{\varepsilon}\right)^{-1 / 2} \Phi^{-1}(\gamma)\right) \tau_{\theta} / 2 \tau_{\varepsilon}$.

43 The result for $\mu_{\theta}$ follows also from a general argument in monotone supermodular games. We know that extremal equilibria of monotone supermodular games are increasing in the posteriors of the players (Van Zandt and Vives (2007)). A sufficient statistic for the posterior of a player under normality is the conditional expectation $E[\theta \mid s]=\left(\tau_{\theta} \mu_{\theta}+\tau_{\varepsilon} s\right) /\left(\tau_{\theta}+\tau_{\varepsilon}\right)$, which is increasing in $\mu_{\theta}$. It follows then that extremal equilibrium thresholds $\left(-\theta^{*},-s^{*}\right)$ increase with $\mu_{\theta}$. 
It follows that $\partial \varphi / \partial \tau_{\varepsilon}<0$ if $\theta^{*}>\mu_{\theta}$ since $\gamma<1 / 2$. Let $\theta^{*}$ be now the largest equilibrium. If $\mu_{\theta}$ is large enough we have $\theta^{*}<\mu_{\theta}$ and the results are reversed.

Proof of Remark 1: When $h(\theta ; \alpha)=h_{0}(\alpha)+h_{1}(\alpha)(\theta-\underset{\sim}{\theta}), \partial h_{0} / \partial \alpha \leq 0$, and $\partial h_{1} / \partial \alpha<0, \quad \theta^{*}-\underset{\sim}{\theta}$ increases with $\alpha$ and decreases with $\gamma$. Note that from $\varphi\left(\theta^{*}\right) \equiv \tau_{\theta}\left(\theta^{*}-\mu_{\theta}\right)-\sqrt{\tau_{\varepsilon}} \Phi^{-1}\left(h\left(\theta^{*}\right)\right)-\sqrt{\tau_{\theta}+\tau_{\varepsilon}} \Phi^{-1}(\gamma)=0, \theta^{*}$ is increasing in $\alpha$ and decreasing in $\gamma$. The result follows since $\partial h_{0} / \partial \alpha \leq 0$ and $\partial h_{1} / \partial \alpha<0$ and therefore $h(\theta ; \alpha)=h_{0}(\alpha)+h_{1}(\alpha)(\theta-\underset{\sim}{\theta})$ is decreasing in $\alpha$ for given $(\theta-\underset{\sim}{\theta})>0$, and $\Phi^{-1}(\cdot)$ is increasing.

Proof of Corollary 1: From the proof of Proposition 1 it follows that the critical ratio $\bar{m}$ fulfils $\quad m=\Phi\left(\frac{\tau_{\theta}}{\sqrt{\tau_{\varepsilon}}}\left(\underset{\sim}{\theta}-\mu_{\theta}\right)-\sqrt{1+\frac{\tau_{\theta}}{\tau_{\varepsilon}}} \Phi^{-1}(\gamma)\right)$ where $\underset{\sim}{\theta} \equiv(1-m) /\left(\ell^{-1}+d^{-1}-m\right)$. (Note that the right hand side is decreasing in $m$ if $\underset{\sim}{\theta} / \partial m<0$, which obtains according to our maintained assumption $1-\ell^{-1}-d^{-1}<0$.) We have also that $\partial \underset{\sim}{\theta} / \partial d>0$, $\partial \underset{\sim}{\theta} / \partial \ell>0$ and $\underset{\sim}{\theta}$ is independent of $\lambda$ and $\gamma$. We know also that $\partial h / \partial m>0$ (under the maintained assumption), $\partial h / \partial \ell^{-1}>0$ and $\partial h / \partial d^{-1}>0$. The results follow from Proposition 2 or by direct inspection of the equilibrium condition $\varphi(\theta)=0$.

\section{Proof of Proposition 3:}

(i) We have that $\operatorname{Pr}(\theta<\underset{\sim}{\theta})=\Phi\left(\sqrt{\tau_{\theta}}\left(\underset{\sim}{\theta}-\mu_{\theta}\right)\right)$ and therefore the solvency constraint (S) $\operatorname{Pr}(\theta<\underset{\sim}{\theta}) \leq q$ holds if and only if $\underset{\sim}{\theta} \leq \underset{\sim}{\theta_{q}} \equiv \mu_{\theta}+\Phi^{-1}(q) / \sqrt{\tau_{\theta}}$ where $\underset{\sim}{\theta} \equiv(1-m) /\left(\ell^{-1}+d^{-1}-m\right)$. Furthermore, $\operatorname{Pr}\left(\theta<\theta^{*}\right)=\Phi\left(\sqrt{\tau_{\theta}}\left(\theta^{*}-\mu_{\theta}\right)\right)$ (where $\theta^{*}$ is the largest equilibrium) and therefore $\operatorname{Pr}\left(\theta<\theta^{*}\right) \leq p$ if and only if $\theta^{*} \leq \theta_{p}^{*} \equiv \mu_{\theta}+\Phi^{-1}(p) / \sqrt{\tau_{\theta}}$. From Corollary 1 we know that the probability of insolvency is decreasing in $m, \ell^{-1}$ and $d^{-1}$. The cutoff $\theta^{*}$ and the probability of a crisis are decreasing in $m, \ell^{-1}$ (and also in $\gamma, d^{-1}$ and $\lambda^{-1}$ ). The constraint $\mathrm{S}$ follows 
immediately from $\quad \underset{\sim}{\theta} \leq \underset{\sim}{\theta_{q}} \equiv \mu_{\theta}+\Phi^{-1}(q) / \sqrt{\tau_{\theta}} \quad$ yielding $\ell^{-1} \geq\left({\underset{\sim}{q}}_{q}\right)^{-1}-d^{-1}-\left(\left({\underset{\sim}{q}}_{q}\right)^{-1}-1\right) m$. Note that $\mathrm{S}$ is independent of $\gamma$ and $\lambda$. The constraint $\mathrm{L}$ follows $\quad$ from $\theta^{*} \leq \theta_{p}^{*} \equiv \mu_{\theta}+\Phi^{-1}(p) / \sqrt{\tau_{\theta}}$ noting that at the boundary $h\left(\theta^{*}\right)=h\left(\theta_{p}^{*}\right)=m+\frac{\ell^{-1}+d^{-1}-m}{\lambda} \theta_{p}^{*}-\frac{1-m}{\lambda}$. It follows that $\mathrm{L}$ is linear $\ell^{-1} \geq \frac{1+k \lambda}{\theta_{p}^{*}}-d^{-1}-\left(\frac{1+\lambda}{\theta_{p}^{*}}-1\right) m \quad$ where, $\quad$ from $\quad \varphi\left(\theta_{p}^{*}\right)=0, \quad$ we $\quad$ obtain $k=h\left(\theta_{p}^{*}\right)=\Phi\left(\frac{\tau_{\theta}}{\sqrt{\tau_{\varepsilon}}}\left(\theta_{p}^{*}-\mu_{\theta}\right)-\sqrt{1+\frac{\tau_{\theta}}{\tau_{\varepsilon}}} \Phi^{-1}(\gamma)\right)=\Phi\left(\sqrt{\frac{\tau_{\theta}}{\tau_{\varepsilon}}} \Phi^{-1}(p)-\sqrt{1+\frac{\tau_{\theta}}{\tau_{\varepsilon}}} \Phi^{-1}(\gamma)\right)$ since $\theta_{p}^{*}-\mu_{\theta}=\Phi^{-1}(p) / \tau_{\theta}$. The constant $k$ is precisely the liquidity ratio which would eliminate the illiquidity region when it is required that $p=q$ and it is induced that $\theta^{*}=\underset{\sim}{\theta}$. We have that $k \in(0,1)$ is increasing in $p$, decreasing in $\gamma$, and with ambiguous dependence on $\tau_{\theta} / \tau_{\varepsilon}$. When $\tau_{\varepsilon}$ is small enough and $p>\gamma, k$ is increasing in $\tau_{\theta} / \tau_{\varepsilon}$. When $\tau_{\varepsilon} \rightarrow \infty, k=1-\gamma$.

Note that when $1-\ell^{-1}-d^{-1}<0$ both constraints $\mathrm{S}$ and $\mathrm{L}$ are downward sloping since then we have $\left(\underset{\sim q}{\theta_{q}}\right)^{-1}-d^{-1}>\left({\underset{\sim}{q}}_{q}\right)^{-1}-1>0$ and $(1+\lambda)\left(\theta_{p}^{*}\right)^{-1}>\left({\underset{\sim}{q}}_{q}\right)^{-1}>1$.

The constraints $\mathrm{S}$ and $\mathrm{L}$ become tighter when $d$ increases. $\mathrm{L}$ becomes tighter when $\lambda$ increases (since $k-m>0$ for interior solutions for $m$ ) or $\gamma$ decreases (since $k$ is decreasing in $\gamma$ ). Both constraints are more relaxed with higher $\mu_{\theta}$ (for S since $\underset{\sim q}{\theta_{q}}$ is increasing in $\mu_{\theta}$ and $m<1$, and for $\mathrm{L}$ since $\partial k / \partial \mu_{\theta}=0$ and $\theta_{p}^{*}$ is increasing in $\mu_{\theta}$, $m<1$ and $k-m>0)$. Increases in $\tau_{\theta}$ increase $\theta_{q}$ and $\theta_{p}^{*}$ provided that $1 / 2>p$ since then $\Phi^{-1}(q)<\Phi^{-1}(p)<0$. This implies that increases in $\tau_{\theta}$ relax $\mathrm{S}$ but have an ambiguous impact on L since $k$ may increase or decrease with $\tau_{\theta}$. A sufficient condition for $k$ to be increasing in $\tau_{\theta}$ is that $\tau_{\varepsilon}$ be small enough and $p>\gamma$. For $p>q, \theta_{p}^{*} /{\underset{\sim}{q}}_{q}$ is decreasing in $\mu_{\theta}$ and therefore $\mathrm{L}$ is relaxed relatively less than $\mathrm{S}$. 
(ii) The minimal $\left(\hat{m}, \hat{\ell}^{-1}\right)$ ratios will be given by the intersection of the boundaries of the solvency

$$
\ell^{-1}=\left({\underset{\sim}{q}}_{q}\right)^{-1}-d^{-1}-\left(\left({\underset{\sim}{\theta}}_{q}\right)^{-1}-1\right) m
$$

and the liquidity

$$
\ell^{-1}=\frac{1+k \lambda}{\theta_{p}^{*}}-d^{-1}-\left(\frac{1+\lambda}{\theta_{p}^{*}}-1\right) m
$$

constraints (note that $\frac{1+k \lambda}{\theta_{p}^{*}}-\left(\underset{\sim q}{\theta_{q}}\right)^{-1}>0$ if $\lambda k>\left(\frac{\theta_{p}^{*}}{{\underset{\sim}{q}}_{q}}-1\right)$ ). We obtain for positive solutions

$$
\begin{gathered}
\hat{m}=1-\frac{1-k}{1-\lambda^{-1}\left({\frac{\theta}{\theta_{p}^{*}}}_{\underset{\sim}{\theta_{q}}}^{*}-1\right)} \text { and } \\
\hat{\ell}^{-1}=\left({\underset{\sim}{q}}_{q}\right)^{-1}-d^{-1}-\left(\left({\underset{\sim}{q}}_{q}\right)^{-1}-1\right) \hat{m} .
\end{gathered}
$$

It follows that $\hat{m}=\max \left\{1-(1-k)\left(1-\lambda^{-1}\left(\frac{\theta_{p}^{*}}{\theta_{q}}-1\right)\right)^{-1}, 0\right\}$ and if $p=q$ then $\hat{m}=k$. Note also that for $p>q$ if $\lambda k>\left(\frac{\theta_{p}^{*}}{\underbrace{}_{q}}-1\right)$ then $k>\hat{m}>0$. The comparative statics of the regulatory ratios given in Table 2 follow: $\partial \hat{m} / \partial \lambda>0, \partial \hat{m} / \partial \gamma<0, \partial \hat{m} / \partial d=0, \partial \hat{\ell}^{-1} / \partial \lambda<0$, $\partial \hat{\ell}^{-1} / \partial \gamma>0$, and $\partial \hat{\ell}^{-1} / \partial d>0$. We have also that $\partial \hat{m} / \partial \mu_{\theta}>0$ since $k$ is independent of $\mu_{\theta}, \partial\left(\theta_{p}^{*} /{\underset{\sim}{q}}_{q}\right) / \partial \mu_{\theta}<0$ (for $p>q$ ), and $\hat{m}$ is decreasing in $\theta_{p}^{*} /{\underset{\sim}{q}}_{q}$. Correspondingly, and since $1-\hat{m}>0$, we obtain that $\partial \hat{\ell}^{-1} / \partial \mu_{\theta}<0$ from $\partial\left(\underset{\sim q}{\theta_{q}}\right)^{-1} / \partial \mu_{\theta}<0$ and $\partial \hat{m} / \partial \mu_{\theta}>0$. The same results hold for an increase in $\tau_{\theta}$ in the case $\tau_{\varepsilon} \rightarrow \infty$ (for which $k=1-\gamma)$ since $\partial\left(\theta_{p}^{*} / \underset{\sim q}{\theta_{q}}\right) / \partial \tau_{\theta}<0$ and $\partial\left(\underset{\sim q}{\theta_{q}}\right)^{-1} / \partial \tau_{\theta}<0$ when $q<1 / 2$. The same applies also if $\tau_{\varepsilon}$ is small enough and $p>\gamma$. Then $k$ increases with $\tau_{\theta}$ and $\partial \hat{m} / \partial \tau_{\theta}>0$. It follows then also that $\partial \hat{\ell}^{-1} / \partial \tau_{\theta}<0$ since 
$\partial \hat{\ell}^{-1} / \partial \tau_{\theta}=-\left(\left({\underset{\sim}{q}}_{q}\right)^{-1}-1\right) \partial \hat{m} / \partial \tau_{\theta}+(1-\hat{m}) \partial\left({\underset{\sim}{q}}_{q}\right)^{-1} / \partial \tau_{\theta}<0 \quad$ as $\quad \partial\left({\underset{\sim}{q}}_{q}\right)^{-1} / \partial \tau_{\theta}<0 \quad$ for $1 / 2>p$. 


\section{References}

Acharya, V., D. Gale and T. Yorulmazer (2010), "Rollover Risk and Market Freezes", forthcoming Journal of Finance.

Acharya V. and O. Merrouche (2010), "Precautionary Hoarding of Liquidity and InterBank Markets: Evidence From the Sub-prime Crisis”, NBER Working Paper 16395.

Acharya, V. and P. Schnabl (2010), "Do Global Banks Spread Global Imbalances? AssetBacked Commercial Paper during the Financial Crisis of 2007-09”, IMF Economic Review, 58, 1, 37-73.

Acharya, V., P. Schnabl and G. Suarez (2011), "Securitization Without Risk Transfer”, mimeo.

Acharya, V. and T. Yorulmazer (2007), "Too Many to Fail - An Analysis of Timeinconsistency in Bank Closure Policies", Journal of Financial Intermediation, 16, $1,1-31$.

Adrian, T. and H. S. Shin (2010), "The Changing Nature of Financial Intermediation and the Financial Crisis of 2007-09”, Staff Report no. 439, Federal Reserve Bank of New York.

Allen, F. and D. Gale (1998), “Optimal Financial Crisis”, Journal of Finance, 53, 4, 1245-1284.

Allen, F. and D. Gale (2004), “Competition and Financial Stability”, Journal of Money, Credit \& Banking, 36, 3, 453-480.

Angeletos, G. and I. Werning (2006), "Crises and Prices: Information Aggregation, Multiplicity, and Volatility", American Economic Review, 96, 5, 1720-1736.

Armantier, O., E. Ghysels, A. Sarkar and J. Shrader (2011), "Stigma in Financial Markets”, FRB of New York Staff Report No. 483.

Bank for International Settlements (2009), Strengthening the Resilience of the Banking Sector, Basel: Bank for International Settlements. 
Bebchuk, L. and I. Goldstein (2011), "Self-Fulfilling Credit Market Freezes", forthcoming Review of Financial Studies.

Bernardo, A. and I. Welch (2004), "Liquidity and Financial Market Runs", Quarterly Journal of Economics", 119, 1, 135-158.

Brunnermeier, M. (2009), "Deciphering the Liquidity and Credit Crunch 2007-2008", Journal of Economic Perspectives, 23, 1, 77-100.

Brunnermeier, M. and L. Pedersen (2009), "Market Liquidity and Funding Liquidity", Review of Financial Studies, 22, 6, 2201-2238.

Bryant, J. (1980), “A Model of Reserves, Bank Runs, and Deposit Insurance?” Journal of Banking \& Finance, 4, 4, 335-344.

Calomiris, C. and C.M. Kahn (1991), "The Role of Demandable Debt in Structuring Optimal Banking Arrangements", American Economic Review, 81, 3, 497-503.

Calomiris, C. and J. Mason (2003), "Fundamentals, Panics, and Bank Distress During the Depression”, American Economic Review, 93, 5, 1615-1647.

Carlsson, H. and E. van Damme (1993), "Global Games Equilibrium Selection", Econometrica, 61, 989-1018.

Chang, R. and A. Velasco (2001), "A Model of Financial Crises in Emerging Markets", Quarterly Journal of Economics, 116, 2, 489-517.

Chari, V. and R. Jagannathan (1988), "Banking Panics, Information, and Rational Expectations Equilibrium", Journal of Finance, 43, 3, 749-761.

Chen, Q., I. Goldstein, W. Jiang (2010), "Payoff Complementarities and Financial Fragility: Evidence from Mutual Fund Outflows", Journal of Financial Economics, 97, 2, 239-262.

Cooper, R. and A. John (1988), "Coordination Failures in Keynesian Models", Quarterly Journal of Economics, 103, 3, 441-463.

Cordella, T. and E. Yeyati (1998), "Public Disclosure and Bank Failures", IMF Staff papers, $45,1,110-131$. 
Corsetti, G. A. Dasgupta, S. Morris, and H. Shin (2004), "Does One Soros Make a Difference? A Theory of Currency Crises with Large and Small Traders." Review of Economic Studies, 71,1, 87-113.

Corsetti, G., B. Guimaraes and N. Roubini (2006), "International Lending of Last Resort and Moral Hazard: A Model of IMF's Catalytic Finance", Journal of Monetary Economics, 53, 3, 441-471.

Covitz, D. M., N. Liang and G. A. Suarez (2009), "The Evolution of a Financial Crisis: Panic in the Asset-Backed Commercial Paper Market." U.S. Federal Reserve Board Finance and Economics Discussion Paper.

Diamond, D. (1984), "Financial Intermediation and Delegated Monitoring", Review of Economic Studies, 51, 166, 393-414.

Diamond, D. and P. Dybvig (1983), "Bank Runs, Deposit Insurance, and Liquidity", Journal of Political Economy, 91, 401-419.

Diamond, D. and R. Rajan (2000), “A Theory of Bank Capital”, Journal of Finance, 55, 6, 2431-2465.

Echenique, F. (2002), "Comparative Statics by Adaptive Dynamics and the Correspondence Principle", Econometrica, 70, 2, 833-844.

Eisenbach, T. (2010), "Rollover Risk: Optimal but Inefficient", mimeo.

Fahlenbrach, R., R. Prilmeier and R. Stulz (2011), "This Time is the Same: Using the Events of 1998 to Explain Bank Returns During the Financial Crisis", mimeo.

Farhi, E. and J. and Tirole (2011), "Collective Moral Hazard, Maturity Mismatch and Systemic Bailouts", mimeo.

Financial Services Authority (2009), The Turner Review. A Regulatory Response to the Global Banking Crisis. London: Financial Services Authority, pp. 126.

Friedman, M., and A. Schwartz (1963), A Monetary History of the United States 18671960. Princeton: Princeton University Press.

Gala, V. and P. Volpin (2010), "Social Value of Information in a Levered Economy", mimeo. 
Gale, D. and X. Vives (2002), "Dollarization, Bailouts, and the Stability of the Banking System”, Quarterly Journal of Economics, 117, 2, 467-502.

Garratt, R. and T. Keister (2009), "Bank Runs as Coordination Failures: An Experimental Study", Journal of Economic Behavior \& Organization, 71, 300-317.

Goldstein, I. and A. Pauzner (2005), "Demand Deposit Contracts and the Probability of Bank Runs”, Journal of Finance, 60, 1293-1328.

Gorton, G. (1985), "Bank Supervision of Convertibility", Journal of Monetary Economics, 15, 177-193.

Gorton, G. (1988), "Banking Panics and Business Cycles”, Oxford Economic Papers, 40, 751-781.

Gorton, G. (2008), "The Panic of 2007”, in Maintaining Stability in a Changing Financial System, Proceedings of the 2008 Jackson Hole Conference, Federal Reserve Bank of Kansas City.

Gorton, G. (2009), “The Subprime Panic”, European Financial Management, 15, 1, 1046.

Gorton, G. and A. Metrick (2010), "Haircuts", Federal Reserve Bank of St. Louis Review, $92,6,507-519$.

He, Z. and W. Xiong (2009), “Dynamic Debt Runs”, mimeo.

Hertzberg, A., J.M. Liberti and D. Paravisini (2011), "Public Information and Coordination: Evidence from a Credit Registry Expansion", Journal of Finance, 66, $2,379-412$.

International Monetary Fund (2008), Global Financial Stability Report.

Ivashina, V. and D. Scharfstein (2010), "Bank Lending during the Financial Crisis of 2008”, Journal of Financial Economics, 97, 319-338.

Jacklin. C. and S. Bhattacharya (1988), "Distinguishing Panics and Information-based Bank Runs: Welfare and Policy Implications”, Journal of Political Economy, 96, 3, 568-592. 
Madies, P. (2006), “An Experimental Exploration of Self-fulfilling Banking Panics: Their Occurrence, Persistence, and Prevention”, Journal of Business, 79, 1831-1866.

Malherbe, F. (2011), “Self-fulfilling Liquidity Dry-ups”, mimeo.

Matutes, C. and X. Vives (1996), "Competition for Deposits, Fragility, and Insurance", Journal of Financial Intermediation, 5, 184-216.

Medrano, L. and X. Vives (2004), "Regulating Insider Trading When Investment Matters", Review of Finance, 2, 8, 199-277.

Morris, S. and H.S. Shin (1998), "Unique Equilibrium in a Model of Self-fulfilling Currency Attacks", American Economic Review, 88, 587-597.

Morris, S. and H.S. Shin (2002), "The Social Value of Public Information", American Economic Review, 92, 1521-1534.

Morris, S. and H.S. Shin (2004), "Coordination Risk and the Price of Debt", European Economic Review, 48, 1, 133-153.

Morris, S. and H.S. Shin (2009), "Illiquidity Component of Credit risk", mimeo.

Pagano, M. and P. Volpin (2009), "Securitization, Transparency and Liquidity", CEPR Discussion Paper \#7105.

Perotti, E. and J. Suárez (2011), “A Pigovian Approach to Liquidity Regulation”, mimeo.

Postlewaite, A. and X. Vives (1987), "Bank Runs as an Equilibrium Phenomenon," Journal of Political Economy, 95, 3, 487-491.

Ratnovski, L. and R. Huang (2009), “Why Are Canadian Banks More Resilient?”, IMF $\mathrm{WP} / 09 / 52$.

Rochet, J. C. and X. Vives (2004), "Coordination Failures and the Lender of Last Resort: Was Bagehot Right After All?", Journal of the European Economic Association, 2, 6, 1116-1147.

Sáez, L. and X. Shi (2004), "Liquidity Pools, Risk Sharing, and Financial Contagion", Journal of Financial Services Research, 25, 1, 5-23. 
Schotter, A., and T. Yorulmazer (2009), "On the Dynamics and Severity of Bank Runs: an Experimental Study", Journal of Financial Intermediation, 18, 2, 217-241.

SEC (2008), "SEC's Oversight of Bear Stearns and Related Entities: Broker-Dealer Risk Assessment Program", SEC Office of the Inspector General Report 446-B.

Shin, H.S. (2009), "Reflections on Northern Rock: The Bank Run that Heralded the Global Financial Crisis”, Journal of Economic Perspectives, 23, 1, 101-119.

Stanton, R. and N. Wallace (2009), “The Bear's Lair: Indexed Credit Default Swaps and the Subprime Mortgage Crisis", mimeo.

Starr, M. and R. Yilmaz (2007), "Bank Runs in Emerging-Market Economies: Evidence from Turkey's Special Finance Houses", Southern Economic Journal, 73, 4, 11121132.

Steiner, J. and J. Sákovics (2009), "Who Matters in Coordination Games ", mimeo.

Tarashev, N. (2007), "Speculative Attacks and the Information Role of the Interest Rate", Journal of the European Economic Association, 5, 1, 1-36.

Van Zandt, T. and X. Vives (2007), "Monotone Equilibria in Bayesian Games of Strategic Complementarities", Journal of Economic Theory, 134, 1, 339-360.

Veronesi, P. and L. Zingales (2010), "Paulson's Gift", Journal of Financial Economics, 97, 3, 339-368.

Vives, X. (2005), "Complementarities and Games: New Developments", Journal of Economic Literature, 43, 437-479.

Vives, X. (2008), Information and Learning in Markets, Princeton: Princeton University Press.

Vives, X. (2010), “Asset Auctions, Information, and Liquidity", Journal of the European Economic Association, 8, 2-3, 467-477.

Vives, X. (2011), “Competition and Stability in Banking”, in Monetary Policy under Financial Turbulence, L. Céspedes, R. Chang and R. Saravia (eds.), Santiago de Chile: Central Bank of Chile. 
Wagner, W. (2007), "Financial Development and the Opacity of Banks", Economics Letters, 97, 1, 6-10.

Winton, A. (1997), "Competition among Financial Intermediaries When Diversification Matters", Journal of Financial Intermediation, 6, 307-346. 